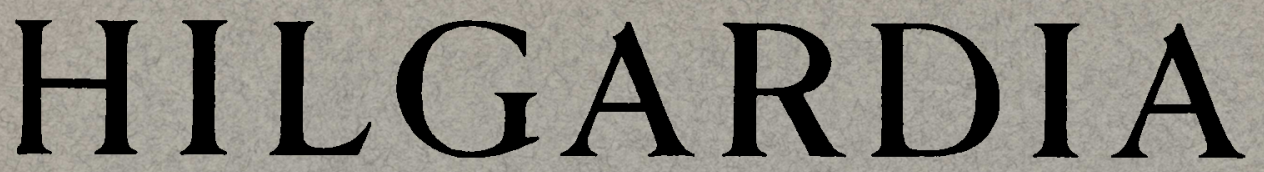

A Journal of Agricultural Science Published by the California Agricultural Experiment Station

CONTENTS

FACTORS INFLUENCING THE EFFECTIVENESS OF SODIUM CHLORATE AS A HERBICIDE

\author{
A. S. CRAFTS
}

THE TOXICITY OF SODIUM ARSENITE AND SODIUM CHLORATE IN FOUR CALIFORNIA SOILS

A. S. CRAFTS 
THE TOXICITY OF SODIUM ARSENITE AND SODIUM CHLORATE IN FOUR

CALIFORNIA SOILS

A. S. CRAFTS 



\title{
THE TOXICITY OF SODIUM ARSENITE AND SODIUM CHLORATE IN FOUR CALIFORNIA SOILS ${ }^{1}$
}

\author{
A. S. CRAFTS 2
}

\section{INTRODUCTION}

SoIL STERILIZATION by means of chemicals has been practiced for many years. Among the agents used, arsenic is the most prominent. Recognized years $\operatorname{ago}^{(8,14)}$ as particularly effective, it has been recommended by many workers ${ }^{(3,7,13,15)}$ for controlling weeds in drives, walks, tennis courts, and various waste areas.

More recently the need for cheap and practical soil-sterilization methods has been indicated by consideration of (1) the dissemination by irrigation waters of the seeds from weeds growing on the ditchbanks, (2) the blocking of irrigation and drainage ditches by overhanging weed growth, (3) the harboring of insect pests and plant diseases by weeds in waste areas, and (4) the fire hazards of dry vegetation near roads, firebreaks, buildings, and fences.

That the methods described in the literature have found such limited use is apparently explained by the lack of fundamental knowledge regarding the behavior of arsenic in soils. There is no basis for interpreting critically the results obtained in the field. When the responses of soils to arsenic treatment are clearly understood and when more satisfactory methods are devised for applying arsenic under field conditions, this chemical should be far more widely used as a soil sterilant.

A satisfactory agent for killing deep-rooted perennial weeds through the soil has long been sought. Åslander ${ }^{(1,2)}$ showed that sodium chlorate may be successfully used for this purpose. Although his results were apparently overlooked in the hurried attempts to solve the country's weed problems by the use of this chemical as a foliage spray, recent works ${ }^{(6,8,10,11)}$ point to soil treatment as the more logical method and indicate the need of a more consistent and reliable control practice than has been existent. Studies on the behavior of sodium chlorate in four western soils should assist materially the formulation of this practice.

\footnotetext{
${ }^{1}$ Received for publication January 10, 1935.

${ }^{2}$ Assistant Botanist in the Experiment Station.
} 


\section{METHODS}

The Soils.-Yolo clay loam, Stockton adobe clay, Fresno sandy loam, and Columbia fine sandy loam were selected for these studies. Samples were taken from the surface 2 inches, screened, sacked, and stored until used. The Columbia and Fresno soils were passed through a 1/8-inch mesh screen; the Yolo and Stockton through a 1/4-inch mesh.

The Yolo clay loam was obtained on the University Farm at Davis. According to Shaw's key, ${ }^{(12)}$ it is a secondary mineral soil with no subsoil accumulations. Composed of material from sedimentary rocks, it is a brown soil of recent origin, with good drainage, very fertile, but heavy in texture and difficult to work when wet.

The Stockton adobe clay, a secondary mineral soil with a lime hardpan, is made up of materials from mixed or undetermined rock sources. It is semimature, black, and developed under restricted drainage. A typical adobe soil, it is high in clay, very sticky when wet, and characterized by extreme shrinkage upon drying. The sample was obtained near the Davis school northeast of Stockton.

The Fresno sandy loam, a secondary mineral soil derived from acid igneous rocks, is mature, with a well-cemented hardpan, brown to gray color, and only fair drainage. The sample was obtained near Hughson in Stanislaus County. It is a valuable agricultural soil, suited to deciduous fruits and many field crops, including alfalfa.

The sample of Columbia fine sandy loam was taken from a peach orchard on the west bank of the Sacramento River about 5 miles north of Broderick. A recent alluvial soil from mixed rock sources, with no definite horizons of removal or deposition, it is light grayish brown, well drained, fertile, and highly productive.

The moisture equivalents of these soils, as determined by Mr. C. H. Hofmann of the Irrigation Division are: Yolo clay loam 31.0, Stockton adobe clay 34.5, Fresno sandy loam 5.9, and Columbia fine sandy loam 19.8.

The Method.-After thorough consideration, the method adopted for studying toxic substances in soils was a biological test using Kanota oats as the indicator. This test gives a direct measure of the toxicity of the reagent without resort to chemical analysis and subsequent interpretation. It has proved simple and effective in determining the relative toxicity of various sterilants, and in studying the effects of time and cropping upon the permanence of their action.

In the toxicity tests a weighed amount ${ }^{3}$ of air-dry soil in a No. 2 can is moistened with a dilute solution of the chemical being tested. For rapid

\footnotetext{
${ }^{3}$ For the Fresno sandy loam 600 grams; for the other three soils 500 grams.
} 
and uniform distribution of the toxicant and water, one-third of the soil in the bottom of the can is moistened with one-third of the solution, a second portion of soil added and moistened, and then the last third added and the final volume of solution poured on. Thus the soil is uni-

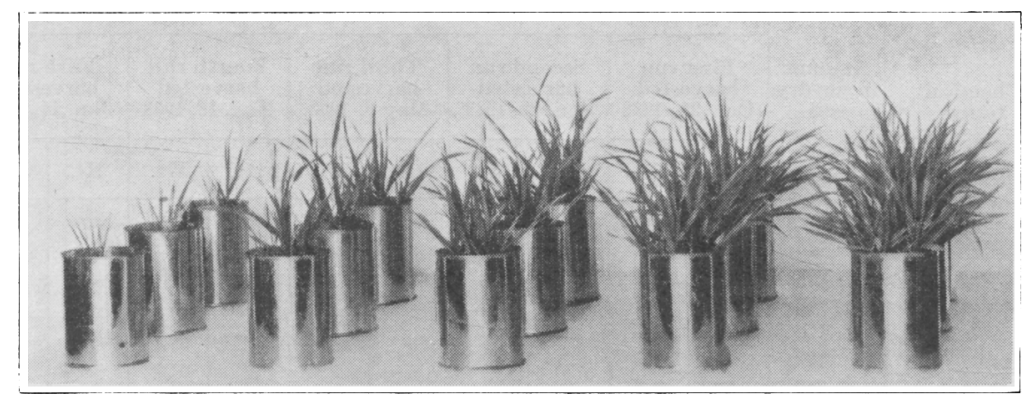

Fig. 1.-A toxicity series with sodium arsenite in Yolo clay loam. Concentrations, from left to right, 540 p.p.m., 405 p.p.m., 270 p.p.m., 135 p.p.m., 0 p.p.m., $\mathrm{As}_{2} \mathrm{O}_{3}$ in the air-dry soil. Three replicates.

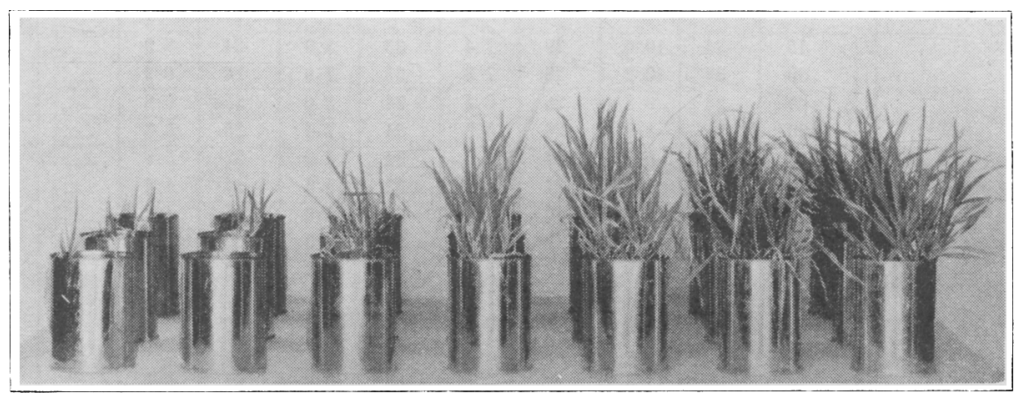

Fig. 2.-A toxicity series with sodium chlorate in Yolo clay loam. Concentrations from left to right, 540 p.p.m., 405 p.p.m., 270 p.p.m., 135 p.p.m., 75 p.p.m., 25 p.p.m., 0 p.p.m., $\mathrm{NaClO}_{3}$ in the air-dry soil. Three replicates.

formly moistened in less than 1 minute. A comparison with cultures in which the finely ground chemical was mixed with air-dry soil and moistened indicated that the chemical also is effectively distributed. The volume of solution used is sufficient to bring the soil to field capacity.

After being moistened, all the cultures are allowed to stand overnight and are then seeded, 13 oats being placed in each can. They germinate in 4 to 5 days and are thinned to 10 plants at the end of about 12 days. The plants are watered by bringing them back to field capacity by weight as often as necessary. The data taken are the height and fresh weight of the plants 30 days from planting. Toward the end of this period a small excess of water is used to insure complete moistening of the soil mass. 
TABLE 1

Preliminary Tests of Chemical Sterilants in Yolo Clay Loam

\begin{tabular}{|c|c|c|c|c|c|c|c|c|c|c|c|}
\hline \multirow{3}{*}{$\begin{array}{c}\text { Chemical } \\
\text { tested }\end{array}$} & \multirow{3}{*}{ 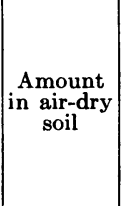 } & \multicolumn{10}{|c|}{ Yield of indicator plants } \\
\hline & & \multicolumn{2}{|c|}{$\begin{array}{c}\text { First run } \\
\text { harvested } \\
\text { Oct. } 29,1932\end{array}$} & \multicolumn{2}{|c|}{$\begin{array}{l}\text { Second run } \\
\text { harvested } \\
\text { Jan. } 22,1933\end{array}$} & \multicolumn{2}{|c|}{$\begin{array}{c}\text { Third run } \\
\text { harvested } \\
\text { May 6, } 1933\end{array}$} & \multicolumn{2}{|c|}{$\begin{array}{c}\text { Fourth run } \\
\text { harvested } \\
\text { Nov. } 18,1933\end{array}$} & \multicolumn{2}{|c|}{$\begin{array}{c}\text { Fifth run } \\
\text { harvested } \\
\text { Jan. 14, 1934 }\end{array}$} \\
\hline & & Ht. & Wt. & Ht. & Wt. & Ht. & Wt. & Ht. & Wt. & Ht. & Wt. \\
\hline \multirow{12}{*}{$\begin{array}{l}\text { Sodium } \\
\text { arsenate.................. }\end{array}$} & p.p.m. & $\mathrm{cm}$ & $g m$ & $\mathrm{~cm}$ & $g m$ & $\mathrm{~cm}$ & $g m$ & $\mathrm{~cm}$ & $g m$ & $\mathrm{~cm}$ & $g m$ \\
\hline & 15 & 29 & 10.3 & ....... & $\ldots \ldots$ & $\ldots . .$. & $\ldots \ldots$ & $\ldots \ldots$ & $\ldots .$. & $\ldots .$. & $\ldots . .$. \\
\hline & 30 & 32 & 10.7 & ....... & $\ldots \ldots$ & $\ldots . .$. & $\ldots \ldots$. & ....... & $\ldots . .$. & ....... & $\ldots \ldots$. \\
\hline & 60 & 32 & 10.7 & ....... & $\ldots \ldots$ & $\ldots . .$. & $\ldots \ldots$ & ....... & $\ldots . .$. & ....... & $\ldots \ldots$ \\
\hline & 120 & 30 & 9.6 & ....... & $\ldots \ldots$. & $\ldots . .$. & $\ldots \ldots$. & ....... & $\ldots . .$. & $\ldots . .$. & $\ldots . .$. \\
\hline & 180 & 31 & 9.5 & ....... & $\ldots \ldots$ & $\ldots \ldots$ & $\ldots \ldots$ & ....... & $\ldots \ldots$. & $\ldots \ldots$. & $\ldots . .$. \\
\hline & 240 & 30 & 8.7 & ....... & $\ldots \ldots$. & $\ldots \ldots$ & $\ldots \ldots$ & ....... & $\ldots \ldots$ & $\ldots \ldots$ & $\ldots \ldots$ \\
\hline & 300 & 30 & 8.0 & ....... & $\ldots \ldots$ & $\ldots . .$. & $\ldots \ldots$ & ....... & $\ldots \ldots$ & $\ldots \ldots$ & $\ldots \ldots$ \\
\hline & 375 & 29 & 7.4 & $\ldots . .$. & $\ldots .$. & $\ldots \ldots$ & $\ldots \ldots$ & ....... & $\ldots .$. & ....... & $\ldots \ldots$ \\
\hline & 450 & 29 & 6.8 & ....... & $\ldots \ldots$ & $\ldots . .$. & $\ldots \ldots$ & $\ldots \ldots$ & $\ldots . .$. & $\ldots . .$. & $\ldots \ldots$ \\
\hline & 600 & 28 & 6.0 & $\ldots . .$. & $\ldots \ldots$ & $\ldots . .$. & $\ldots \ldots$ & $\ldots . .$. & $\ldots . .$. & $\ldots . .$. & $\ldots \ldots$ \\
\hline & Check & 30 & 9.6 & ....... & $\ldots \ldots$ & $\ldots \ldots$ & $\ldots \ldots$ & ....... & $\ldots .$. & ....... & $\ldots \ldots$ \\
\hline \multirow{11}{*}{$\begin{array}{l}\text { Sodium } \\
\text { arsenite. }\end{array}$} & 15 & 34 & 10.6 & 29 & 7.4 & 35 & 8.9 & 24 & 6.9 & $\ldots \ldots$. & $\ldots \ldots$ \\
\hline & 30 & 33 & 10.2 & 29 & 7.3 & 35 & 7.9 & 24 & 6.9 & $\ldots . .$. & $\ldots \ldots$ \\
\hline & 60 & 33 & 9.8 & 28 & 6.5 & 34 & 8.0 & 25 & 6.9 & $\ldots \ldots$ & $\ldots \ldots$ \\
\hline & 120 & 31 & $8.9^{\circ}$ & 26 & 5.5 & 34 & 7.4 & 25 & 6.3 & $\ldots . .$. & $\ldots \ldots$ \\
\hline & 180 & 29 & 6.2 & 24 & 4.5 & 34 & 5.9 & 22 & 5.9 & ....... & $\ldots \ldots$ \\
\hline & 240 & 29 & 6.2 & 22 & 4.1 & 33 & 5.3 & 24 & 4.4 & $\ldots \ldots$. & $\ldots \ldots$ \\
\hline & 300 & 29 & 4.7 & 20 & 4.0 & 32 & 5.6 & 25 & 4.7 & ....... & $\ldots \ldots$ \\
\hline & 375 & 20 & 3.8 & 17 & 2.9 & 30 & 4.3 & 22 & 3.4 & $\ldots . .$. & $\ldots \ldots$. \\
\hline & 450 & 10 & 0.9 & 15 & 2.3 & 30 & 4.3 & 22 & 3.4 & $\ldots \ldots$ & $\ldots \ldots$ \\
\hline & 600 & 5 & 0.1 & 12 & 1.6 & 28 & 3.6 & 22 & 3.1 & $\ldots . .$. & $\ldots \ldots$ \\
\hline & Check & 31 & 10.5 & 28 & 7.4 & 35 & 8.7 & 26 & 7.1 & ....... & $\ldots .$. \\
\hline \multirow{11}{*}{$\begin{array}{l}\text { Sodium } \\
\text { chlorate.. }\end{array}$} & 15 & 33 & 11.3 & ........ & $\ldots \ldots$ & 36 & 8.9 & 24 & 6.6 & ....... & $\ldots \ldots$ \\
\hline & 30 & 33 & 10.8 & $\ldots \ldots$. & $\ldots \ldots$ & 35 & 8.8 & 26 & 7.1 & $\ldots \ldots$. & $\ldots .$. \\
\hline & 60 & 31 & 10.2 & ....... & $\ldots \ldots$ & 35 & 8.4 & 27 & 7.7 & $\ldots . .$. & $\ldots \ldots$ \\
\hline & 120 & 30 & 8.4 & $\ldots . .$. & $\ldots \ldots$ & 34 & 7.9 & 27 & 7.6 & $\ldots \ldots$. & $\ldots . .$. \\
\hline & 180 & 28 & 5.9 & $\ldots . .$. & $\ldots \ldots$ & 33 & 7.7 & 27 & 7.1 & $\ldots . .$. & $\ldots \ldots$ \\
\hline & 240 & 25 & 4.9 & $\ldots .$. & $\ldots \ldots$ & 33 & 6.8 & 27 & 7.1 & $\ldots \ldots$. & $\ldots \ldots$ \\
\hline & 300 & 23 & 3.8 & ....... & $\ldots \ldots$ & 32 & 5.9 & 26 & 6.5 & $\ldots . .$. & $\ldots . .$. \\
\hline & 375 & 20 & 2.8 & $\ldots \ldots$ & $\ldots \ldots$ & 31 & 5.5 & 25 & 5.5 & $\ldots . .$. & $\ldots \ldots$ \\
\hline & 450 & 18 & 2.5 & $\ldots . .$. & $\ldots \ldots$ & 29 & 4.3 & 24 & 5. 0 & $\ldots . .$. & $\ldots .$. \\
\hline & 600 & 15 & 1.4 & $\ldots \ldots$ & $\ldots . .$. & 28 & 3.0 & 24 & 4.3 & $\ldots \ldots$. & $\ldots \ldots$ \\
\hline & Check & 30 & 9.7 & $\ldots . .$. & $\cdots \cdots$ & 33 & 8.2 & 25 & 6.9 & ....... & $\ldots \ldots$ \\
\hline \multirow{11}{*}{$\begin{array}{c}\text { Thallium } \\
\text { sulfate.... }\end{array}$} & 15 & 28 & 9.6 & ........ & $\ldots \ldots$ & 35 & 8.8 & ....... & $\ldots . .$. & 29 & 5.2 \\
\hline & 30 & 28 & 8.6 & ....... & $\ldots . .$. & 35 & 8.7 & ....... & $\ldots . .$. & 30 & 5.8 \\
\hline & 60 & 25 & 5.1 & ....... & ....... & 31 & 5.6 & ....... & $\ldots . .$. & 30 & 4.6 \\
\hline & 120 & 20 & 1.8 & ....... & $\ldots \ldots$ & 23 & 2.9 & ....... & $\ldots .$. & 22 & 3.2 \\
\hline & 180 & 15 & 1.0 & ....... & $\ldots \ldots$ & 18 & 1.7 & ....... & $\ldots . .$. & 16 & 2.2 \\
\hline & 240 & 10 & 0.5 & ....... & $\ldots \ldots$ & 10 & 0.6 & $\ldots . .$. & $\ldots . .$. & 12 & 1.5 \\
\hline & 300 & 7 & 0.4 & $\ldots . .$. & $\ldots \ldots$ & 8 & 0.5 & $\ldots \ldots$. & $\ldots . .$. & 12 & 1.2 \\
\hline & 375 & 4 & 0.2 & $\ldots . .$. & $\ldots . .$. & 7 & 0.4 & ....... & $\ldots . .$. & 11 & 0.9 \\
\hline & 450 & 3 & 0.1 & ....... & $\ldots \ldots$ & 5 & 0.2 & $\ldots \ldots$ & $\ldots \ldots$ & 10 & 0.6 \\
\hline & 600 & 3 & 0.1 & $\ldots \ldots$. & $\ldots \ldots$ & 3 & 0.2 & $\ldots \ldots$ & $\ldots .$. & 8 & 0.5 \\
\hline & Check & 28 & 9.4 & ....... & $\ldots \ldots$ & 33 & 8.3 & ....... & $\ldots . .$. & 30 & 5.3 \\
\hline
\end{tabular}


In harvesting, the height of the plants is measured, a visual estimate being made of an average value. They are then cut off at the surface of the soil, broken into pieces about 3 inches in length, and weighed on an analytical balance. After weighing the plants are returned to the can from which they were taken.

Figure 1 presents a series selected to show the type of response ob-

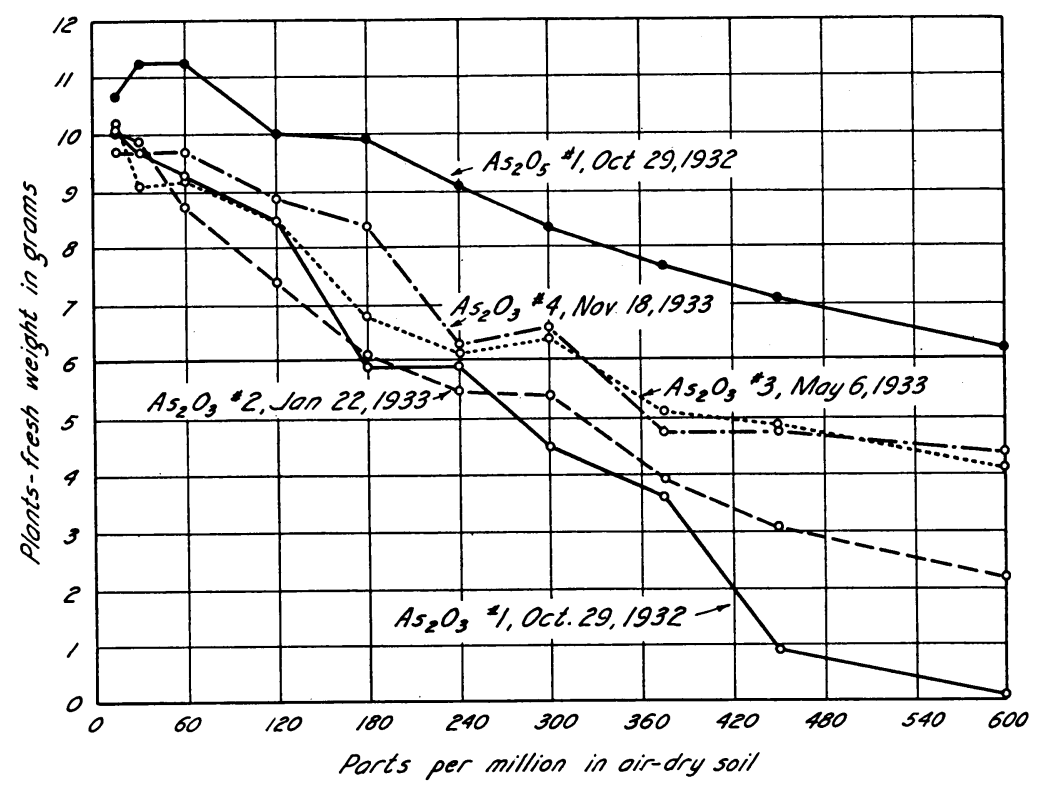

Fig. 3.-The relation of crop yield to the concentration of the arsenate and arsenite of sodium in Yolo clay loam.

tained with sodium arsenite; figure 2, a similar series with sodium chlorate.

After harvest, the cultures are air-dried for 30 days, and the soils are pulverized and remoistened, the previous crop being placed in the bottom of the can where it decomposes rapidly. They are seeded and handled as in the first run. This process is repeated as often as necessary for studying the behavior of the chemical with continued cropping.

Preliminary Toxicity Tests.-The first test to be described is a comparison in Yolo clay loam of the toxicities of several chemicals. The concentrations used are indicated in table 1, expressed as parts of chemical per million parts of air-dry soil. All of the test cultures were replicated three times; some of the checks were replicated six times. The values given are the arithmetic averages of the replicates.

For comparative purposes these data are expressed on the basis of 
$\mathrm{As}_{2} \mathrm{O}_{5}$ for the sodium arsenate, $\mathrm{As}_{2} \mathrm{O}_{3}$ for the sodium arsenite, $\mathrm{NaClO}_{3}$ for the sodium chlorate, and $\mathrm{Tl}_{2} \mathrm{SO}_{4}$ for the thallium sulfate. The data from table 1 are presented as graphs in figures 3 and 4 . In all toxicity tests concentrations are given in parts per million of air-dry soil. Obviously the sodium arsenate is inferior as a soil sterilant. The trivalent arsenic is more toxic even after four croppings than the equivalent

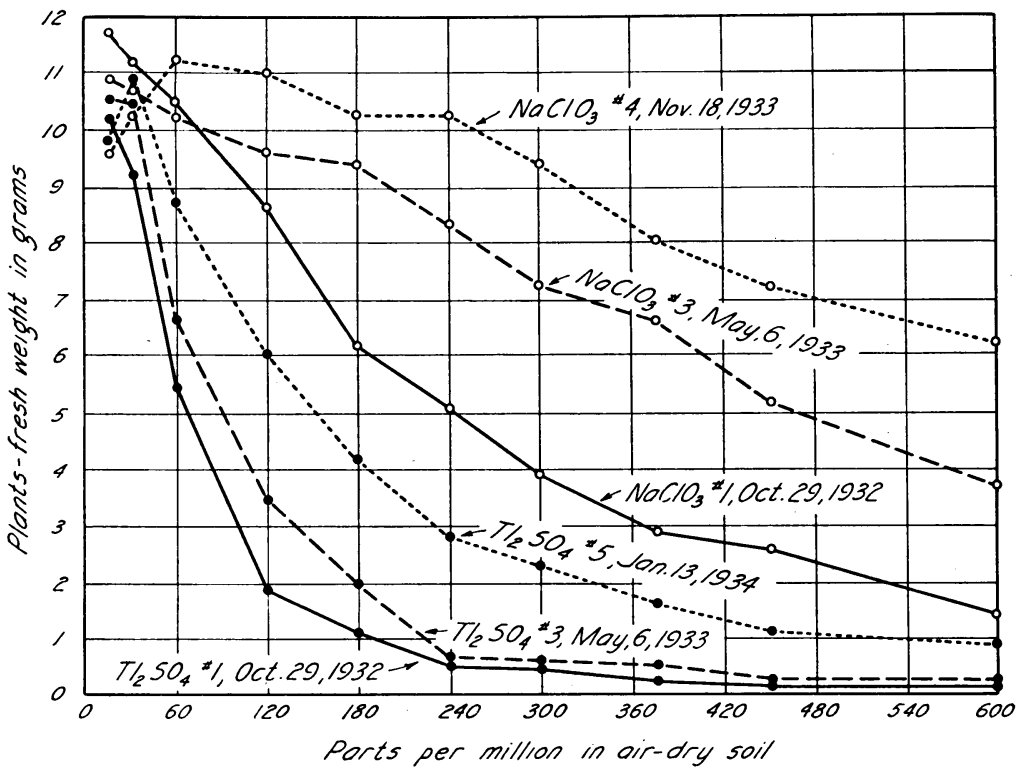

Fig. 4.-The relation of crop yield to the concentration of sodium chlorate and thallium sulfate in Yolo clay loam.

amount of the arsenate. Sodium chlorate compares very well with the arsenite but loses its toxicity more rapidly. Since the crop is returned to the can and nothing is lost from these cultures, this decrease in toxicity probably represents decomposition of the chlorate and fixation in a form unavailable to plants in the case of arsenite. Thallium sulfate is the most toxic of the chemicals tried: even with the fifth cropping, it is more effective than sodium arsenite. It also is gradually rendered unavailable to plants. Since sodium arsenite is the least expensive of these chemicals, it is the most practical for use in soil sterilization.

\section{STUDIES WITH SODIUM ARSENITE}

Judging by the variable results of numerous plot tests with sodium arsenite on California soils, definite knowledge concerning the toxicity and the fixing by the soil of this chemical must precede its use in soil- 
sterilization practice. As the following experiments show, these properties vary widely in different soils; the results with the four distinct

TABLE 2

Toxicity of Sodium Arsenite in Four California Solls, as Shown by Growth of Indicator Plants

\begin{tabular}{|c|c|c|c|c|c|c|c|c|}
\hline \multirow{2}{*}{$\begin{array}{l}\text { Sodium arsenite } \\
\text { expressed as } \\
\text { p.p.m. } \mathrm{As}_{2} \mathrm{O}_{3} \text { in } \\
\text { air-dry soil }\end{array}$} & \multicolumn{2}{|c|}{ Yolo clay loam } & \multicolumn{2}{|c|}{$\begin{array}{l}\text { Stockton adobe } \\
\text { clay }\end{array}$} & \multicolumn{2}{|c|}{$\begin{array}{l}\text { Columbia fine } \\
\text { sandy loam }\end{array}$} & \multicolumn{2}{|c|}{ Fresno sandy loam } \\
\hline & Height & Weight & Height & Weight & Height & Weight & Height & Weight \\
\hline
\end{tabular}

First run harvested June 10, 1933

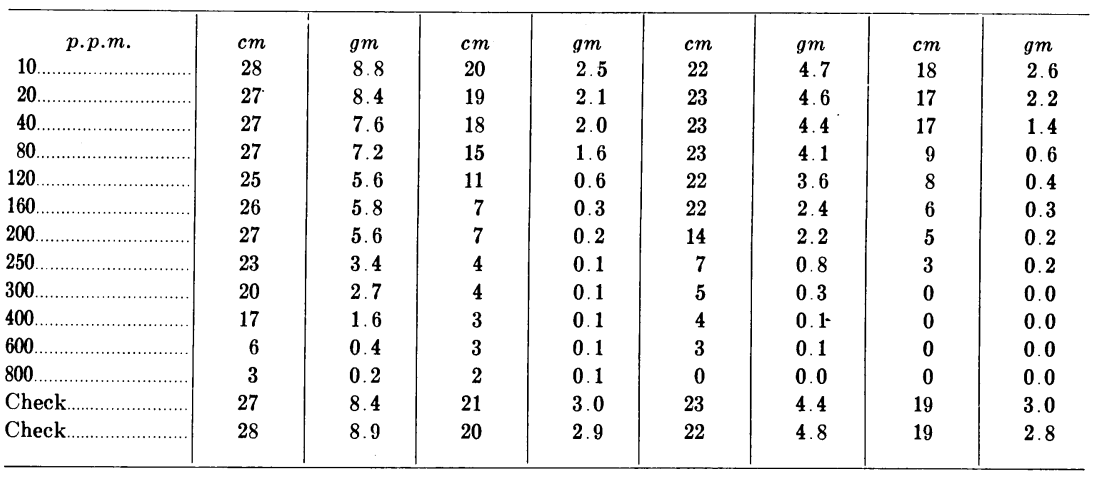

Third run harvested November 1.6, 1933

\begin{tabular}{|c|c|c|c|c|c|c|c|c|}
\hline p.p.m. & $\begin{array}{l}\text { cm } \\
31\end{array}$ & $\begin{array}{l}g m \\
7.8\end{array}$ & $\begin{array}{l}\mathrm{cm} \\
23\end{array}$ & $\begin{array}{l}g m \\
3.1\end{array}$ & $\begin{array}{l}c m \\
30\end{array}$ & $\begin{array}{l}g m \\
7.1\end{array}$ & $\begin{array}{l}c m \\
27\end{array}$ & $\begin{array}{l}g m \\
4.8\end{array}$ \\
\hline $20 \ldots \ldots \ldots \ldots$ & 32 & 8.1 & 22 & 3.0 & 30 & 6.8 & 27 & 4.7 \\
\hline $40 \ldots$ & 32 & 8.5 & 23 & 2.9 & 30 & 7.1 & 27 & 4.6 \\
\hline $80 \ldots$ & 32 & 7.9 & 23 & 2.9 & 30 & 6.6 & 27 & 3.9 \\
\hline $120 \ldots$ & 32 & 7.7 & 22 & 2.8 & 29 & 5.9 & 24 & 2.8 \\
\hline $160 \ldots \ldots$ & 33 & 7.0 & 22 & 2.3 & 29 & 5.5 & 22 & 1.9 \\
\hline $200 \ldots \ldots \ldots \ldots$ & 32 & 6.7 & 20 & 2.2 & 28 & 4.6 & 21 & 1.8 \\
\hline $250 \ldots$ & 31 & 6.4 & 19 & 2.0 & 26 & 3.5 & 18 & 1.5 \\
\hline $300 \ldots$ & 30 & 5.4 & 17 & 1.9 & 25 & 3.1 & 17 & 1.5 \\
\hline 400 . & 29 & 4.3 & 14 & 1.5 & 22 & 2.2 & 14 & 0.9 \\
\hline 600 . & 27 & 3.6 & 10 & 0.6 & 21 & 1.9 & 9 & 0.3 \\
\hline $800 \ldots$ & 24 & 2.8 & 8 & 0.3 & 16 & 1.3 & 7 & 0.2 \\
\hline Check... & 32 & 8.6 & 23 & 3.0 & 27 & 6.6 & 28 & 4.9 \\
\hline Check... & 33 & 8.6 & 22 & 2.8 & 29 & 7.1 & 27 & 4.7 \\
\hline
\end{tabular}

soil types used do not enable one, at present, to predict the behavior of arsenic in untested soil.

Toxicity Tests.--The toxicity of sodium arsenite was studied in the four soils previously described. The results appear in table 2 . Three crops were grown in these cultures; and the data for the first and third are given, the second being intermediate between them. All cultures were replicated five times, and the values presented are averages of the 
five replicates. These data are illustrated in figures 5 and 6 . For comparative purposes, the curves for the third run have been reduced to the base of the first run by multiplying all values by the factor

\section{Weight of first-run checks}

The soils used in these tests differ widely in crop-producing power

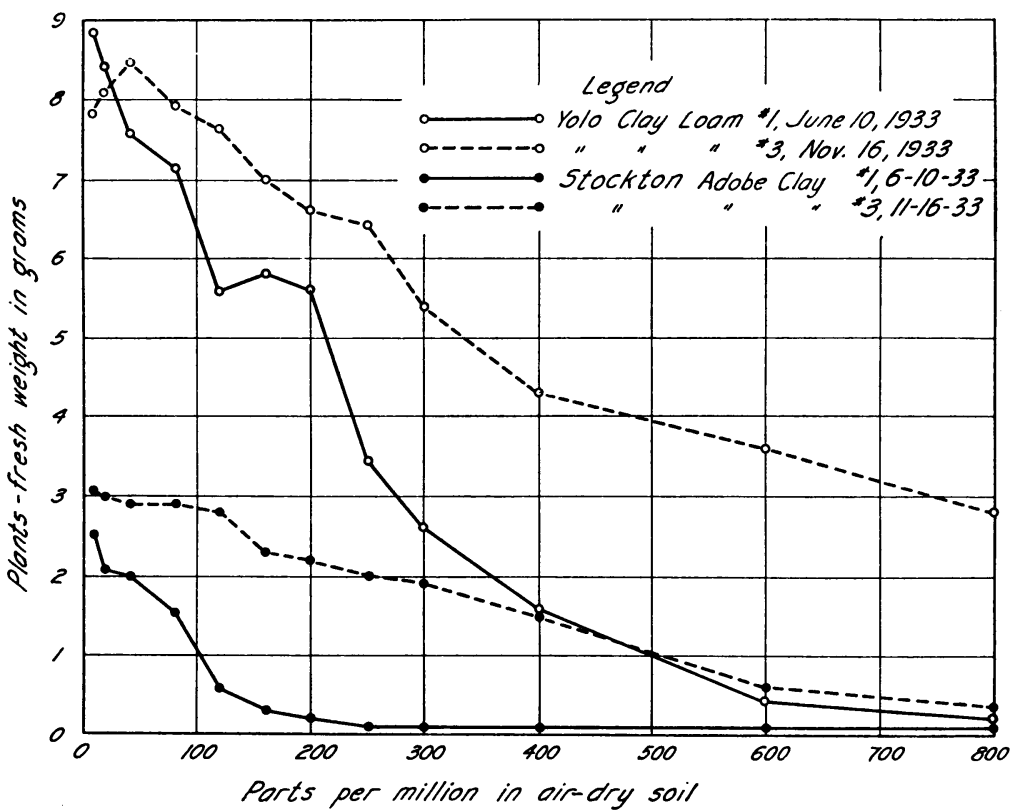

Fig. 5.-The relation of crop yield to the concentration of sodium arsenite expressed as $\mathrm{As}_{2} \mathrm{O}_{3}$ in Yolo clay loam and Stockton adobe clay.

under the conditions of the experiment. The two recent soils, Yolo clay loam and Columbia fine sandy loam, are very productive, the difference between them probably resulting mainly from the difference in texture. A Yolo fine sandy loam used in some other tests has given check plants very similar to those produced by the Columbia fine sandy loam of these experiments. On the other hand, the two more mature soils, though almost at the opposite extremes with regard to textural grade, produce very similar crops. The plants evidence a lack of nitrogen and fail to thrive after the first two weeks. The weather was cooler and growing conditions in the greenhouse were better in November than in June. This fact apparently favored growth of the plants in the two sandy soils but had little effect on those in the clays.

Concerning the toxicity of arsenic in these soils, two features are very prominent. In the first place, the differences in initial toxicity are large. 
As shown by greenhouse tests on soils from sterile field plots, when the ten plants in a can weigh 1 gram or less, the soil may be considered sterile for all practical purposes, the weight of these small plants being made up chiefly of the stored material from the seed. If a weight of 1 gram or less is taken as the criterion of sterility, Stockton adobe clay (fig. 5) containing 100 p.p.m. of $\mathrm{As}_{2} \mathrm{O}_{3}$ is sterile, whereas 500 p.p.m. are re-

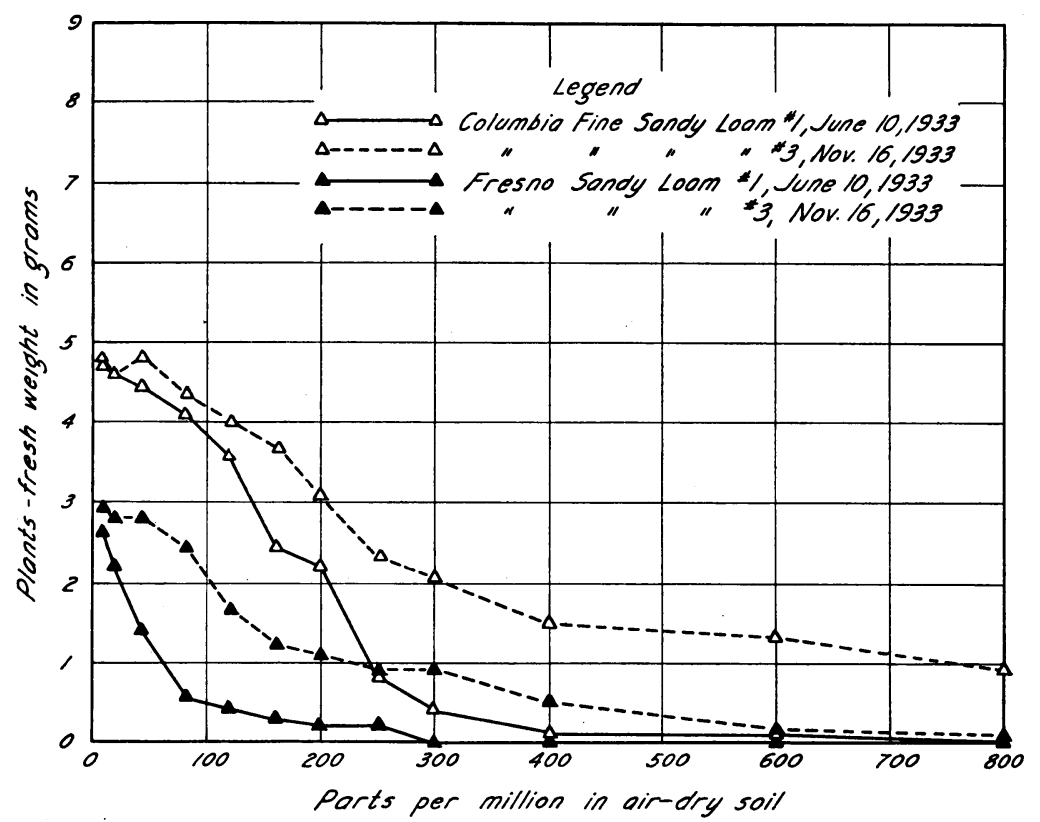

Fig. 6.-The relation of erop yield to the concentration of sodium arsenite expressed as $\mathrm{As}_{2} \mathrm{O}_{3}$ in Columbia fine sandy loam and Fresno sandy loam.

quired in Yolo clay loam. In Fresno sandy loam (fig. 6) 60 p.p.m. suffice, whereas in the Columbia fine sandy loam 240 p.p.m. are needed. These differences, related fundamentally to the chemical and physical nature of the soils, definitely limit the practicability of a soil-sterilization program where sodium arsenite is being used. Many anomalies of the fieldplot tests may be satisfactorily explained by these findings, which, though they do not take the place of a comprehensive survey on the toxicity of arsenic in soils, point the way to such a survey and indicate its necessity.

The second interesting point about these curves is the large loss of toxicity where no arsenic is lost from the cultures. Much arsenic is evidently rendered unavailable to plants after its application to the soil. This fact probably explains the rapid decrease in effectiveness of light applications of arsenic in the field. 
The Soil-Tube Tests.-Besides the initial toxicity, the ability of the soil to fix arsenic in a form available to plants is important in soil sterilization. This property of the soil determines the effective depth to which

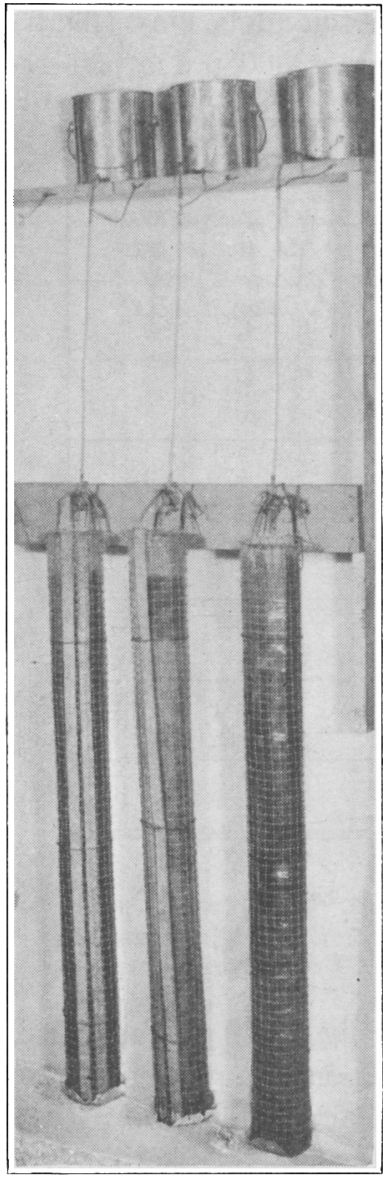

Fig. 7.-Apparatus for the soil-tube tests. Screw clamps are used to adjust the rate of flow. The center tube has been moistened only to a depth of about 5 inches. The other two are completely moist. Three of the ten units are shown. a given arsenic dosage will penetrate and its resistance to leaching rains.

A special type of soil tube greatly facilitates the study of the fixing power of soils for toxic chemicals. This tube consists of a celluloid sheet 10 inches wide and 36 inches long, bent to form a hollow cylinder and surrounded by a support of 1/2-inch mesh hardware cloth. In making up the tube, the lining and wire support are both lapped and the latter wired. A piece of filter paper held against the end by a square of $1 / 8$-inch mesh hardware cloth closes the tube at the bottom. By laying the tube on a table and cutting the wires it can be opened and the soil removed in discrete fractions.

In the studies on the capacities of soils to hold arsenic, tubes filled with air-dry soil are slowly moistened from the top by dripping solutions on them until they are wet to the bottom. The apparatus used holds ten tubes, and solutions of the toxicant of varying concentrations are applied. In all soil-tube tests concentrations are given in parts per million in the applied solutions. A standard rate of moistening of 12 drops per minute from standard tips has been used. Figure 7 illustrates the moistening of the soil tubes. The soils are moistened in 24 to 48 hours, according to the volume of solution held.

When a complete set has been moistened, the tubes are allowed to stand for 24 hours and are then opened; the soil column is divided into weighed fractions. While moisture distribution is not uniform within this time, experiments have shown that the lack of uniformity has no measurable effect upon the location of the chemical. Each fraction having been mixed and placed in a No. 2 can, the cultures are seeded and handled as in the previously described experiments. 
The results of a complete series of these tests are given in table 3. Each culture represents a fraction of the soil column about 4 inches in height, and the 36-inch column yields nine such cultures. In the table the column headed "Depth" designates the location within the tube of the different

TABLE 3

The Fixing Power of Four California Soils for Sodium Arsenite, as Shown by Growth of Indicator Plants

\begin{tabular}{|c|c|c|c|c|c|c|c|c|c|c|c|c|c|}
\hline \multirow{2}{*}{ Soil type } & \multirow{2}{*}{ Depth } & \multicolumn{2}{|c|}{$\underset{\text { check }}{\mathrm{H}_{2} \mathrm{O}}$} & \multicolumn{2}{|c|}{$\begin{array}{c}\mathrm{Ass}_{2} \mathrm{O}_{3} \\
100 \text { p.p.m. }\end{array}$} & \multicolumn{2}{|c|}{$\begin{array}{c}\mathrm{Ass}_{2} \mathrm{O}_{3} \\
200 \text { p.p.m. }\end{array}$} & \multicolumn{2}{|c|}{$\begin{array}{c}\mathrm{Ass}_{2} \mathrm{O}_{3} \\
400 \text { p.p.m. }\end{array}$} & \multicolumn{2}{|c|}{$\begin{array}{c}\mathrm{As}_{2} \mathrm{O}_{3} \\
800 \text { p.p.m. }\end{array}$} & \multicolumn{2}{|c|}{$\begin{array}{c}\mathrm{As}_{2} \mathrm{O}_{3} \\
1200 \text { p.p.m. }\end{array}$} \\
\hline & & Ht. & Wt. & Ht. & Wt. & Ht. & Wt. & Ht. & Wt. & Ht. & Wt. & Ht. & Wt. \\
\hline \multirow{11}{*}{$\begin{array}{l}\text { Yolo clay loam; } \\
\text { harvested } \\
\text { June } 15,1933\end{array}$} & inches & $\mathrm{cm}$ & $g m$ & $\mathrm{~cm}$ & $g m$ & $\mathrm{~cm}$ & $g m$ & $\mathrm{~cm}$ & $g m$ & $\mathrm{~cm}$ & $g m$ & $\mathrm{~cm}$ & $g m$ \\
\hline & $0-4$ & 20 & 4.2 & 8 & 0.6 & 5 & 0.1 & 4 & 0.1 & 2 & 0.0 & 1 & 0.0 \\
\hline & $4-8$ & 22 & 4.6 & 21 & 4.0 & 17 & 1.7 & 5 & 0.2 & 3 & 0.2 & 2 & 0.0 \\
\hline & $8-12$ & 22 & 5.3 & 22 & 4.8 & 22 & 4.8 & 21 & 3.5 & 6 & 0.2 & 5 & 0.1 \\
\hline & $12-16$ & 23 & 5.8 & 22 & 5.5 & 23 & 5.3 & 23 & 4.8 & 23 & 5.4 & 23 & 4.1 \\
\hline & $16-20$ & 24 & 6.4 & 23 & 6.0 & 25 & 6.5 & 23 & 4.8 & 24 & 6.1 & 24 & 5.6 \\
\hline & $20-24$ & 24 & 6.4 & 24 & 7.1 & 26 & 8.0 & 25 & 5.5 & 26 & 6.5 & 24 & 6.3 \\
\hline & $24-28$ & 24 & 8.1 & 26 & 8.5 & 27 & 8.6 & 25 & 6.8 & 25 & 7.4 & 25 & 6.8 \\
\hline & $28-32$ & 25 & 7.1 & 27 & 7.7 & 26 & 7.6 & 29 & 8.8 & 28 & 7.5 & 25 & 6.9 \\
\hline & $32-36$ & 24 & 6.4 & 24 & 5.6 & 24 & 5.5 & 26 & 4.1 & 23 & 5.3 & 24 & 5.3 \\
\hline & Check* & 24 & 6.4 & 24 & 6.6 & 25 & 6.8 & 25 & 7.2 & 24 & 6.0 & 24 & 6.5 \\
\hline \multirow{10}{*}{$\begin{array}{l}\text { Stockton } \\
\text { adobe clay; } \\
\text { harvested } \\
\text { July } 12,1933\end{array}$} & $0-4$ & 17 & 2.9 & 6 & 0.1 & 3 & 0.1 & 3 & 0.1 & 0 & 0.1 & 0 & 0.0 \\
\hline & $4-8$ & 16 & 2.6 & 13 & 1.6 & 8 & 0.4 & 6 & 0.1 & 1 & 0.1 & 0 & 0.0 \\
\hline & $8-12$ & 15 & 2.8 & 15 & 2.5 & 16 & 2.3 & 14 & 1.6 & 5 & 0.1 & 3 & 0.1 \\
\hline & $12-16$ & 16 & 2.6 & 15 & 2.6 & 16 & 2.3 & 15 & 1.8 & 9 & 0.8 & 5 & 0.1 \\
\hline & $16-20$ & 15 & 2.6 & 17 & 2.7 & 16 & 2.6 & 16 & 2.0 & 18 & 3.2 & 15 & 2.5 \\
\hline & $20-24$ & 15 & 2.6 & 16 & 2.5 & 17 & 2.8 & 16 & 2.6 & 17 & 2.6 & 17 & 2.7 \\
\hline & $24-28$ & 15 & 2.5 & 14 & 2.6 & 16 & 2.5 & 17 & 3.0 & 16 & 3.0 & 16 & 2.9 \\
\hline & $28-32$ & 15 & 2.8 & 16 & 2.9 & 17 & 2.7 & 17 & 3.1 & 16 & 2.6 & 17 & 3.1 \\
\hline & $32-36$ & 14 & 2.5 & 14 & 2.6 & 17 & 2.9 & 17 & 2.9 & 17 & 3.0 & 17 & 3.2 \\
\hline & Check* & 18 & 2.6 & 18 & 2.4 & 18 & 2.8 & 18 & 2.9 & 19 & 2.9 & 19 & 2.7 \\
\hline \multirow{10}{*}{$\begin{array}{l}\text { Columbia fine } \\
\text { sandy loam; } \\
\text { harvested } \\
\text { July } 23,1933\end{array}$} & $0-4$ & 22 & 3.5 & 7 & 0.5 & 5 & 0.2 & 5 & 0.1 & 0 & 0.0 & 0 & 0.0 \\
\hline & $4-8$ & 24 & 3.8 & 20 & 2.4 & 10 & 0.8 & 6 & 0.4 & 0 & 0.0 & 0 & 0.0 \\
\hline & $8-12$ & 26 & 4.0 & 24 & 3.9 & 25 & 4.1 & 14 & 1.8 & 0 & 0.0 & 0 & 0.0 \\
\hline & $12-16$ & 24 & 3.4 & 25 & 4.0 & 24 & 3.6 & 22 & 3.4 & 28 & 4.0 & 16 & 1.4 \\
\hline & $16-20$ & 26 & 4.0 & 26 & 4.4 & 26 & 3.9 & 26 & 3.9 & 27 & 4.1 & 27 & 4.3 \\
\hline & $20-24$ & 25 & 4.0 & 26 & 4.2 & 26 & 4.1 & 28 & 4.7 & 26 & 4.1 & 28 & 4.3 \\
\hline & $24-28$ & 24 & 3.9 & 27 & 4.3 & 28 & 4.4 & 28 & 4.5 & 28 & 4.8 & 29 & 4.7 \\
\hline & 28-32 & 25 & 4.4 & 27 & 4.1 & 28 & 4.8 & 29 & 4.9 & 28 & 4.6 & 28 & 4.2 \\
\hline & $32-36$ & 30 & 6.3 & 28 & 5.0 & 29 & 5.5 & 30 & 5.8 & 32 & 6.8 & 30 & 4.8 \\
\hline & Check* & 27 & 4.0 & 29 & 4.7 & 29 & 4.6 & 30 & 4.8 & 28 & 4.4 & 27 & 4.0 \\
\hline \multirow{10}{*}{$\begin{array}{l}\text { Fresno sandy } \\
\text { loam; } \\
\text { harvested } \\
\text { June } 29,1933\end{array}$} & $0-4$ & 18 & 3.1 & 10 & 0.5 & 7 & 0.2 & 4 & 0.1 & 4 & 0.1 & 0 & 0.0 \\
\hline & $4-8$ & 21 & 3.4 & 14 & 0.8 & 9 & 0.3 & 6 & 0.2 & 5 & 0.1 & 4 & 0.1 \\
\hline & $8-12$ & 18 & 3.3 & 18 & 2.5 & 16 & 1.3 & 10 & 0.5 & 5 & 0.2 & 4 & 0.1 \\
\hline & $12-16$ & 21 & 3.7 & 19 & 3.0 & 20 & 3.4 & 18 & 2.5 & 7 & 0.3 & 6 & 0.1 \\
\hline & $16-20$ & 21 & 3.3 & 19 & 3.2 & 19 & 3.2 & 18 & 3.2 & 19 & 2.6 & 17 & 1.3 \\
\hline & $20-24$ & 21 & 3.9 & 20 & 3.8 & 19 & 3.5 & 19 & 3.4 & 18 & 3.1 & 19 & 3.4 \\
\hline & 24-28 & 21 & 3.7 & 19 & 3.5 & 18 & 3.6 & 19 & 3.6 & 18 & 3.1 & 18 & 2.8 \\
\hline & $28-32$ & 18 & 3.3 & 18 & 3.0 & 19 & 3.1 & 18 & 2.8 & 17 & 3.3 & 16 & 2.5 \\
\hline & $32-36$ & 16 & 3.4 & 17 & 3.7 & 15 & 3.0 & 17 & 3.3 & 16 & 3.1 & 16 & 2.7 \\
\hline & Check* & 19 & 3.4 & 20 & 3.7 & 20 & 3.6 & 19 & 3.6 & 20 & 3.6 & 21 & 3.7 \\
\hline
\end{tabular}

* These checks were cultures in air-dry soil moistened and planted, with no other treatment. 
fractions. When the crop is very small, the arsenic is present in a lethal concentration; in the remainder of the column the arsenic is absent, or present only in sublethal amounts. In the Yolo and Columbia soils the crop in the lower fractions is above that of the checks because of leaching of readily soluble nutrients. Such materials were apparently absent from the Stockton and Fresno soils. The checks given at the bottom of

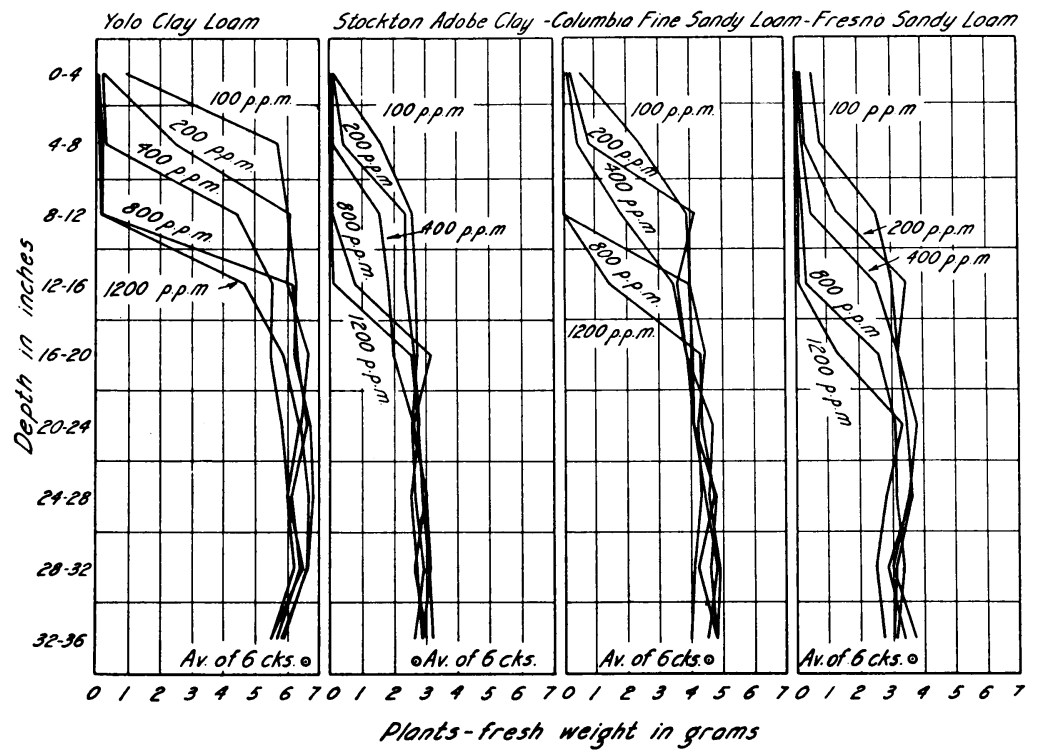

Fig. 8. - The relation of crop yield to penetration of sodium arsenite into columns of four California soils, showing their fixing power for this chemical.

each soil are simply cultures made up of the air-dry soils moistened with water and planted.

The results are shown in figure 8. By means of check tubes moistened with water alone, and notes on the depth of penetration of the solutions, the graphs of the results in the Yolo and Columbia soils have been corrected for the leaching of nutrients, since this effect only lends confusion to the curves and has nothing to do with the toxicity of the sterilant. The results on the four soils do not appear to differ very much; but when the amount of water required to moisten the columns is considered, the capacities of the soils will be found to vary considerably.

Considering that practically all the arsenic applied to these tubes is held in the fractions showing reduced growth, and that the amount originally present in the water occupying the fractions showing normal growth is a measure of the amount fixed, values have been computed (table 4) for the fixing power of these soils for arsenious ions when ap- 
plied as dilute solutions of sodium arsenite. Obviously, these soils differ widely in fixing power for arsenic in the form applied. The capacity of the Yolo soil was approximately twice that of the Stockton and Columbia soils and about four times that of the Fresno sandy loam. With increasing concentrations of the solution applied, furthermore, the amount of chemical held was greater, more than twice as much being fixed from the solution of 1,200 p.p.m. as from that containing 100 p.p.m. Judging by these results, the depth of penetration of a given dosage de-

TABLE 4

The Fixing Power of Four California Solls for Arsenious Arsenic, Expressed in Parts of $\mathrm{As}_{2} \mathrm{O}_{3}$ Per Million Parts of Air-Dry SoIL

\begin{tabular}{|c|c|c|c|c|c|c|c|}
\hline \multirow{3}{*}{ Soil type } & \multirow{3}{*}{$\begin{array}{c}\text { Air-dry } \\
\text { soil per tube, } \\
\text { in kilos }\end{array}$} & \multirow{3}{*}{$\begin{array}{l}\text { Solution } \\
\text { per tube, } \\
\text { in cc }\end{array}$} & \multicolumn{5}{|c|}{$\begin{array}{c}\text { Concentration of } \mathrm{As}_{2} \mathrm{O}_{3} \text { in applied solution, in } \\
\text { parts per million of solution }\end{array}$} \\
\hline & & & 100 & 200 & 400 & 800 & 1,200 \\
\hline & & & \multicolumn{5}{|c|}{$\begin{array}{c}\mathrm{As}_{2} \mathrm{O}_{3} \text { fixed by the soil, in parts per million } \\
\text { of air-dry soil }\end{array}$} \\
\hline Yolo clay loam... & 5.0 & 1,500 & 270 & 278 & 372 & 480 & 622 \\
\hline Stockton adobe clay.... & 6.0 & 1,400 & 138 & 180 & 272 & 280 & 350 \\
\hline Columbia sandy loam & 5.5 & 1,150 & 114 & 167 & 218 & 335 & 380 \\
\hline Fresno sandy loam....... & 6.5 & 850 & 56 & 64 & 105 & 131 & 150 \\
\hline
\end{tabular}

pends not alone upon the amount applied but also upon the type of soil and upon the concentration in which the arsenic moves through the upper soil layers.

The effects of leaching upon the concentration and distribution of arsenic in soil columns has been studied by slightly modifying the technic just described. Tubes of the soils were slowly moistened with a sodium arsenite solution containing 400 p.p.m. of $\mathrm{As}_{2} \mathrm{O}_{3}$. After the initial moistening, distilled water was applied at the same rate as the solution, varying amounts of water being added to the different tubes in a series. When flow from the tubes had ceased, they were removed from the rack shown in figure 7 and allowed to stand in air-dry soil until all excess moisture had drained away. They were then opened. The soil was divided, placed in nine cans, and planted as before. The data from these experiments appear in tables 5, 6, 7, and 8 and figures 9 and 10 .

Here again there are fundamental differences in the response of the four soils to this leaching treatment. In the Yolo clay loam 5 surface centimeters of water moved the chemical into the third fraction in lethal concentration, and 10 surface centimeters moved it into the fourth fraction. With 20 and 40 surface centimeters there was little further change. As the amount of leaching was again doubled, the available arsenic was 
washed from the fourth fraction and reduced in the third; and with 160 surface centimeters it was further reduced in the third and somewhat lowered in the second. Through all this leaching, arsenic remained in the top fraction in lethal concentration.

TABLE 5

Results of Leaching Sodium Arsenite in Yolo Clay Loam, as Shown by Growth of Indicator Plants (Harvested June 25, 1933)

\begin{tabular}{|c|c|c|c|c|c|c|c|c|c|c|c|c|c|c|}
\hline \multirow{2}{*}{ Depth } & \multicolumn{2}{|c|}{$0 \mathrm{~cm} \mathrm{H}_{2} \mathrm{O}$} & \multicolumn{2}{|c|}{$5 \mathrm{~cm} \mathrm{H}_{2} \mathrm{O}$} & \multicolumn{2}{|c|}{$10 \mathrm{~cm} \mathrm{H}_{2} \mathrm{O}$} & \multicolumn{2}{|c|}{$20 \mathrm{~cm} \mathrm{H}_{2} \mathrm{O}$} & \multicolumn{2}{|c|}{$40 \mathrm{~cm} \mathrm{H}_{2} \mathrm{O}$} & \multicolumn{2}{|c|}{$80 \mathrm{~cm} \mathrm{H}_{2} \mathrm{O}$} & \multicolumn{2}{|c|}{$160 \mathrm{~cm} \mathrm{H}_{2} \mathrm{O}$} \\
\hline & Ht. & Wt. & Ht. & Wt. & Ht. & Wt. & Ht. & Wt. & Ht. & Wt. & Ht. & Wt. & Ht. & Wt. \\
\hline \multicolumn{15}{|c|}{$\mathrm{As}_{2} \mathrm{O}_{3}-400$ p.p.m. in moistening solution } \\
\hline inches & $\mathrm{cm}$ & $g m$ & $\mathrm{~cm}$ & $g m$ & $\mathrm{~cm}$ & $g m$ & $\mathrm{~cm}$ & $g m$ & $\mathrm{~cm}$ & $g m$ & $\mathrm{~cm}$ & $g m$ & $\mathrm{~cm}$ & $g m$ \\
\hline $0-4$ & 4 & 0.1 & 5 & 0.2 & 4 & 0.1 & 5 & 0.1 & 8 & 0.2 & 7 & 0.2 & 6 & 0.2 \\
\hline 4-8 & 5 & 0.2 & 11 & 0.6 & 11 & 0.7 & 11 & 1.1 & 9 & 0.4 & 7 & 0.3 & 18 & 1.1 \\
\hline $8-12$ & 21 & 3.5 & 9 & 0.6 & 11 & 1.1 & 13 & 1.0 & 12 & 0.6 & 14 & 1.4 & 16 & 2.2 \\
\hline $12-16$ & 23 & 4.8 & 19 & 3.2 & 14 & 1.0 & 13 & 0.7 & 11 & 0.8 & 22 & 4.8 & 22 & 4.3 \\
\hline $16-20$ & 23 & 4.8 & 23 & 4.8 & 19 & 3.2 & 22 & 5.0 & 22 & 4.1 & 24 & 5.3 & 23 & 5.5 \\
\hline $20-24$ & 25 & 5.5 & 21 & 4.9 & 21 & 5.6 & 23 & 5.2 & 24 & 5.2 & 24 & 5.9 & 23 & 4.9 \\
\hline 24-28 & 25 & 6.8 & 20 & 4.7 & 19 & 4.3 & 22 & 4.8 & 23 & 4.8 & 25 & 5.6 & 23 & 5.2 \\
\hline 28-32 & 29 & 8.8 & 21 & 4.6 & 21 & 4.8 & 21 & 4.6 & 23 & 4.8 & 24 & 5.4 & 24 & 5.1 \\
\hline $32-36$ & 26 & 4.1 & 22 & 6.0 & 20 & 5.0 & 20 & 4.6 & 21 & 4.7 & 25 & 5.8 & 23 & 5.4 \\
\hline
\end{tabular}

\begin{tabular}{|c|c|c|c|c|c|c|c|c|c|c|c|c|c|c|}
\hline \multicolumn{15}{|c|}{ Check tubes-moistened with water } \\
\hline inches & $\mathrm{cm}$ & $g m$ & $\mathrm{~cm}$ & $g m$ & $\mathrm{~cm}$ & $g m$ & $\mathrm{~cm}$ & $g m$ & $\mathrm{~cm}$ & $g m$ & $\mathrm{~cm}$ & $g m$ & $\mathrm{~cm}$ & $g m$ \\
\hline $0-4$ & $\ldots$ & $\ldots \ldots$ & 19 & 4.7 & 19 & 4.3 & $\ldots$ & $\ldots \ldots$. & 22 & 4.8 & & $\ldots \ldots$ & 21 & 4.7 \\
\hline $4-8$ & $\ldots$. & $\ldots \ldots$. & 21 & 5.5 & 20 & 4.5 & $\ldots$. & $\ldots \ldots$ & 22 & 5.5 & $\ldots$ & $\ldots \ldots$. & 21 & 5.5 \\
\hline $8-12$ & $\ldots$. & $\ldots \ldots$ & 22 & 5.6 & 20 & 5.2 & $\ldots$ & $\ldots . .$. & 21 & 5.3 & $\ldots$. & $\ldots \ldots$ & 21 & 5.1 \\
\hline $12-16$ & $\ldots$ & $\ldots \ldots$ & 22 & 5.4 & 20 & 5.0 & $\ldots$ & $\ldots . .$. & 22 & 6.0 & $\ldots$ & $\ldots . .$. & 22 & 5.0 \\
\hline $16-20$ & $\ldots$. & $\ldots \ldots$ & 22 & 5.5 & 21 & 5.0 & $\ldots$. & $\ldots \ldots$. & 21 & 4.8 & $\ldots$ & $\ldots . .$. & 22 & 5.3 \\
\hline $20-24$ & $\ldots$ & ....... & 23 & 5.6 & 21 & 5.5 & $\ldots$ & $\ldots \ldots$ & 22 & 5.4 & $\ldots$ & ....... & 22 & 5.0 \\
\hline $24-28$ & $\ldots$. & $\ldots \ldots$. & 23 & 6.2 & 21 & 5.6 & $\ldots$. & $\ldots . .$. & 22 & 5.4 & $\ldots$. & $\ldots . .$. & 21 & 4.6 \\
\hline 28-32 & $\ldots$. & $\ldots \ldots$. & 22 & 5.7 & 23 & 6.4 & $\ldots$. & $\ldots . .$. & 21 & 5.0 & $\ldots$ & $\ldots . .$. & 20 & 4.9 \\
\hline $32-36$ & $\ldots$. & $\ldots \ldots$. & 24 & 7.2 & 23 & 7.1 & $\ldots$. & $\ldots . .$. & 20 & 4.6 & $\ldots$ & $\ldots . .$. & 20 & 4.4 \\
\hline Check* & 25 & 7.2 & 26 & 8.2 & 25 & 7.8 & 24 & 6.7 & 25 & 8.0 & 25 & 6.9 & $\ldots$ & ....... \\
\hline
\end{tabular}

* These checks were cultures in air-dry soil moistened and planted, with no other treatment. Average weight of the $6=7.5$ grams.

In the Stockton adobe clay the arsenic was considerably more mobile. Each increase in the volume of water applied moved the arsenic downward, until with 160 surface centimeters it was present in the lowest fraction in lethal concentration. With this highest volume, however, it had begun to decrease in concentration in the upper fraction; and further leaching would undoubtedly have washed more and more of it from the top of the column.

In the Columbia fine sandy loam the movement was greater than in the Yolo soil, but somewhat less than in the Stockton soil. Growth was not completely inhibited in the lowest fraction even after leaching with 
160 surface centimeters of water, but it had increased a bit in the upper fractions.

The toxicant moved most readily in the Fresno sandy loam. Although considerably less arsenic was applied to this soil than to the others, be-

TABLE 6

Results of Leaching Sodium Arsenite in Stockton adobe Clay, as Shown by Growth of Indicator Plants

(Harvested July 23, 1933)

\begin{tabular}{|c|c|c|c|c|c|c|c|c|c|c|c|c|c|c|}
\hline \multirow{2}{*}{ Depth } & \multicolumn{2}{|c|}{$0 \mathrm{~cm} \mathrm{H}_{2} \mathrm{O}$} & \multicolumn{2}{|c|}{$5 \mathrm{~cm} \mathrm{H}_{2} \mathrm{O}$} & \multicolumn{2}{|c|}{$10 \mathrm{~cm} \mathrm{H}_{2} \mathrm{O}$} & \multicolumn{2}{|c|}{$20 \mathrm{~cm} \mathrm{H}_{2} \mathrm{O}$} & \multicolumn{2}{|c|}{$40 \mathrm{~cm} \mathrm{H}_{2} \mathrm{O}$} & \multicolumn{2}{|c|}{$80 \mathrm{~cm} \mathrm{H}_{2} \mathrm{O}$} & \multicolumn{2}{|c|}{$160 \mathrm{~cm} \mathrm{H}_{2} \mathrm{O}$} \\
\hline & $\mathrm{Ht}$. & Wt. & Ht. & Wt. & Ht. & Wt. & Ht. & Wt. & Ht. & Wt. & Ht. & Wt. & Ht. & Wt. \\
\hline \multicolumn{15}{|c|}{$\mathrm{As}_{2} \mathrm{O}_{3}-400$ p.p.m. in moistening solution } \\
\hline inches & $\mathrm{cm}$ & $g m$ & $\mathrm{~cm}$ & $g m$ & $\mathrm{~cm}$ & $g m$ & $\mathrm{~cm}$ & $g m$ & $\mathrm{~cm}$ & $g m$ & $\mathrm{~cm}$ & $g m$ & $\mathrm{~cm}$ & $g m$ \\
\hline $0-4$ & 3 & 0.1 & 0 & 0.0 & 4 & 0.1 & 4 & 0.1 & 5 & 0.1 & 7 & 0.2 & 10 & 0.8 \\
\hline $4-8$ & 6 & 0.1 & 3 & 0.1 & 4 & 0.1 & 3 & 0.1 & 5 & 0.1 & 6 & 0.1 & 8 & 0.2 \\
\hline $8-12$ & 14 & 1.6 & 7 & 0.1 & 5 & 0.1 & 4 & 0.1 & 5 & 0.1 & 5 & 0.1 & 6 & 0.1 \\
\hline $12-16$ & 15 & 1.8 & 14 & 2.2 & 8 & 0.3 & 6 & 0.1 & 5 & 0.1 & 7 & 0.1 & 8 & 0.2 \\
\hline $16-20$ & 16 & 2.0 & 13 & 1.9 & 13 & 1.7 & 9 & 0.6 & 7 & 0.1 & 6 & 0.1 & 7 & 0.1 \\
\hline $20-24$ & 16 & 2.6 & 14 & 1.8 & 14 & 1.9 & 13 & 1.7 & 12 & 1.1 & 7 & 0.1 & 9 & 0.1 \\
\hline 24-28 & 17 & 3.0 & 15 & 1.9 & 14 & 2.0 & 15 & 2.3 & 14 & 2.1 & 14 & 1.3 & 8 & 0.3 \\
\hline $28-32$ & 17 & 3.1 & 13 & 1.9 & 13 & 1.8 & 14 & 1.7 & 14 & 2.0 & 12 & 1.3 & 7 & 0.1 \\
\hline $32-36$ & 17 & 2.9 & 10 & 1.3 & 12 & 1.3 & 13 & 1.5 & 13 & 1.7 & 10 & 0.9 & 7 & 0.2 \\
\hline
\end{tabular}

Check tubes-moistened with water

\begin{tabular}{|c|c|c|c|c|c|c|c|c|c|c|c|c|c|c|}
\hline inches & $\mathrm{cm}$ & $g m$ & $\mathrm{~cm}$ & $g m$ & $\mathrm{~cm}$ & $g m$ & $\mathrm{~cm}$ & $g m$ & $\mathrm{~cm}$ & $g m$ & $\mathrm{~cm}$ & $g m$ & $\mathrm{~cm}$ & $g m$ \\
\hline $0-4$ & $\ldots$. & $\ldots \ldots$ & 12 & 1.3 & 13 & 1.6 & $\ldots$ & ....... & 13 & 1.9 & $\ldots$ & $\ldots \ldots$ & 15 & 2.2 \\
\hline $4-8$ & $\ldots$ & ....... & 12 & 1.6 & 13 & 1.8 & $\ldots$ & ....... & 14 & 2.0 & $\ldots$ & $\ldots \ldots$. & 14 & 2.1 \\
\hline $8-12$ & $\ldots$ & $\ldots \ldots$. & 13 & 1.7 & 12 & 1.9 & $\ldots$ & ....... & 14 & 2.1 & $\ldots$ & $\ldots \ldots$ & 15 & 2.0 \\
\hline $12-16$ & $\ldots$ & ....... & 13 & 1.8 & 13 & 1.8 & $\ldots$ & ........ & 14 & 2.0 & $\ldots$ & $\ldots \ldots$ & 14 & 1.9 \\
\hline $16-20$ & $\ldots$ & $\ldots \ldots$ & 13 & 1.9 & 14 & 2.2 & $\ldots$ & ....... & 14 & 1.9 & $\ldots$. & $\ldots . .$. & 15 & 2.2 \\
\hline $20-24$ & $\ldots$ & $\ldots \ldots$ & 12 & 1.6 & 13 & 1.9 & $\ldots$ & ....... & 15 & 2.3 & $\ldots$. & $\ldots \ldots$. & 14 & 2.2 \\
\hline 24-28 & $\ldots$ & ....... & 12 & 1.7 & 14 & 2.0 & $\ldots$ & ....... & 14 & 1.9 & $\ldots$ & ........ & 15 & 2.1 \\
\hline $28-32$ & $\ldots$ & ....... & 14 & 2.0 & 13 & 2.0 & $\ldots$. & ....... & 12 & 1.9 & $\ldots$ & ....... & 15 & 2.1 \\
\hline $32-36$ & $\ldots$. & $\ldots \ldots$ & 13 & 1.6 & 12 & 1.8 & $\ldots$ & ....... & 12 & 1.4 & $\ldots$. & ....... & 15 & 2.2 \\
\hline Check* & 18 & 2.9 & 16 & 2.4 & 17 & 2.5 & 16 & 2.1 & 17 & 2.5 & 18 & 2.7 & $\ldots$ & ....... \\
\hline
\end{tabular}

* These checks were cultures in air-dry soil moistened and planted, with no other treatment. Average weight of the $6=2.5$ grams.

cause of the small volume of solution required to moisten the soil column, and although the total toxic effect was somewhat less pronounced, the chemical had started to move out of the top fraction after leaching with 20 surface centimeters of water; and with 160 surface centimeters it was mostly lost from the soil. This is a distinctly different behavior from that of the other three soils.

Discussion of Sodium Arsenite Studies.-The data presented in this paper, though quantitative for the experiments described, will require careful interpretation before they can be used in practical work. In the field, sterilized soils are subject to numerous and complex influences 
that tend to alter the effects of a given treatment in a variety of ways. The plants that attempt to grow in these soils find conditions altogether different from those of the greenhouse. The common method of applying

TABLE 7

Results of Leaching Sodium Arsenite in Columbia Fine Sandy Loam, as Shown by Growth of Indicator Plants

(Harvested February 3, 1934)

\begin{tabular}{|c|c|c|c|c|c|c|c|c|c|c|c|c|c|c|}
\hline \multirow{2}{*}{ Depth } & \multicolumn{2}{|c|}{$0 \mathrm{~cm} \mathrm{H}_{2} \mathrm{O}$} & \multicolumn{2}{|c|}{$5 \mathrm{~cm} \mathrm{H}_{2} \mathrm{O}$} & \multicolumn{2}{|c|}{$10 \mathrm{~cm} \mathrm{H}_{2} \mathrm{O}$} & \multicolumn{2}{|c|}{$20 \mathrm{~cm} \mathrm{H}_{2} \mathrm{O}$} & \multicolumn{2}{|c|}{$40 \mathrm{~cm} \mathrm{H}_{2} \mathrm{O}$} & \multicolumn{2}{|c|}{$80 \mathrm{~cm} \mathrm{H} \mathrm{H}_{2} \mathrm{O}$} & \multicolumn{2}{|c|}{$160 \mathrm{~cm} \mathrm{H}_{2} \mathrm{O}$} \\
\hline & Ht. & Wt. & Ht. & Wt. & Ht. & Wt. & Ht. & Wt. & Ht. & Wt. & Ht. & Wt. & Ht. & Wt. \\
\hline \multicolumn{15}{|c|}{$\mathrm{As}_{2} \mathrm{O}_{3}-400$ p.p.m. in moistening solution } \\
\hline inches & $\mathrm{cm}$ & $g m$ & $\mathrm{~cm}$ & $g m$ & $\mathrm{~cm}$ & $g m$ & $\mathrm{~cm}$ & $g m$ & $\mathrm{~cm}$ & $g m$ & $\mathrm{~cm}$ & $g m$ & $\mathrm{~cm}$ & $g m$ \\
\hline $0-4$ & 5 & 0.1 & 6 & 0.3 & 6 & 0.3 & 8 & 0.6 & 11 & 0.8 & 12 & 1.2 & 14 & 1.3 \\
\hline 4.8 & 6 & 0.4 & 7 & 0.4 & 7 & 0.4 & 7 & 0.5 & 8 & 0.5 & 11 & 0.9 & 14 & 1.6 \\
\hline $8-12$ & 14 & 1.8 & 14 & 1.1 & 10 & 0.7 & 8 & 0.5 & 8 & 0.5 & 12 & 0.9 & 15 & 1.3 \\
\hline $12-16$ & 22 & 3.4 & 21 & 3.8 & 23 & 3.5 & 11 & 0.8 & 8 & 0.5 & 11 & 0.7 & 14 & 1.4 \\
\hline $16-20$ & 26 & 3.9 & 23 & 4.2 & 25 & 3.3 & 23 & 3.4 & 10 & 0.6 & 10 & 0.6 & 10 & 0.7 \\
\hline $20-24$ & 28 & 4.7 & 26 & 4.6 & 24 & 4.0 & 25 & 4.1 & 23 & 3.0 & 10 & 0.6 & 11 & 0.9 \\
\hline $24-28$ & 28 & 4.5 & 25 & $\begin{array}{l}4.0 \\
3.9\end{array}$ & 25 & 3.8 & 25 & 4.0 & 25 & 4.0 & 10 & 0.6 & 11 & 0.7 \\
\hline 28-32 & 29 & 4.9 & 25 & 4.8 & 25 & 3.8 & 26 & 4.1 & 25 & 3.9 & 13 & 1.1 & 11 & 0.7 \\
\hline $32-36$ & 30 & 5.8 & 24 & 4.5 & 25 & 4.5 & 26 & 4.2 & 24 & 3.5 & 18 & 2.3 & 12 & 1.0 \\
\hline
\end{tabular}

Check tubes-moistened with water

\begin{tabular}{|c|c|c|c|c|c|c|c|c|c|c|c|c|c|c|}
\hline inches & $\mathrm{cm}$ & $g m$ & $\mathrm{~cm}$ & $g m$ & $\mathrm{~cm}$ & $g m$ & $\mathrm{~cm}$ & $g m$ & $\mathrm{~cm}$ & $g m$ & $\mathrm{~cm}$ & $g m$ & $\mathrm{~cm}$ & $g m$ \\
\hline $0-4$ & $\ldots .$. & ....... & 21 & 3.2 & 24 & 3.2 & $\ldots$. & ........ & 21 & 3.4 & .... & ........ & 22 & 2.6 \\
\hline $4-8$ & $\ldots$. & $\ldots . . .$. & 24 & 4.5 & 25 & 4.3 & $\ldots$. & ........ & 24 & 3.8 & $\ldots$. & $\ldots \ldots$. & 21 & 2.6 \\
\hline $8-12$ & $\ldots$. & $\ldots . .$. & 23 & 3.7 & 24 & 3.9 & $\ldots$. & ....... & 24 & 3.4 & $\ldots$. & ....... & 22 & 3.0 \\
\hline $12-16$ & $\ldots$. & ....... & 25 & 4.5 & 20 & 3.2 & .... & ....... & 23 & 3.1 & .... & ....... & 23 & 3.3 \\
\hline $16-20$ & $\ldots$. & $\ldots . .$. & 24 & 4.3 & 23 & 3.0 & .... & $\ldots . .$. & 22 & 3.1 & $\ldots$ & ....... & 22 & 3.1 \\
\hline $20-24$ & $\ldots$ & ....... & 24 & 4.6 & 23 & 3.1 & .... & ....... & 24 & 3.3 & .... & $\ldots . .$. & 22 & 3.3 \\
\hline $24-28$ & $\ldots$ & ....... & 25 & 4.2 & 25 & 3.6 & $\ldots$ & ....... & 24 & 3.8 & $\ldots$ & ....... & 21 & 3.1 \\
\hline 28-32 & $\ldots$ & $\ldots . . .$. & 26 & 4.5 & 26 & 4.1 & $\ldots$. & ....... & 23 & 3.3 & $\ldots$. & ....... & 21 & 2.7 \\
\hline $32-36$ & $\ldots$ & $\ldots . .$. & 24 & 4.0 & 24 & 4.0 & $\ldots$. & $\ldots . .$. & 22 & 3.1 & $\ldots$ & ....... & 20 & 2.8 \\
\hline Check* & 30 & 4.8 & 26 & 4.3 & 28 & 4.6 & 24 & 4.2 & 27 & 4.0 & 26 & 4.3 & $\ldots$ & $\ldots . .$. \\
\hline
\end{tabular}

* These checks were cultures in air-dry soil moistened and planted, with no other treatment. Average weight of the $6=4.4$ grams.

arsenic to the soil, furthermore, differs from that used in the experiments.

On the other hand, certain responses observed in this work are fundamental and will occur, though with a possible variation in degree, wherever arsenious arsenic comes in contact with soils.

As compared with other common sterilants, sodium arsenite is superior from several angles. It is as toxic as sodium chlorate in equivalent dosages, and is less subject to losses from decomposition and leaching. Though less toxic than thallium sulfate, it is by far the most economical chemical, on a cost basis, to use for soil sterilization.

In practical soil sterilization the differences in toxicity of arsenic in 
different soil types are of fundamental importance. As plot tests have demonstrated, 2 pounds of $\mathrm{As}_{2} \mathrm{O}_{3}$ per square rod are as effective on Fresno sandy loam as 8 pounds on Yolo clay loam. Though these two types probably represent the extremes of a large number of agricul-

TABLE 8

Results of Leaching Sodium Arsenite in Fresno Sandy Loam, as Shown by Growth of Indicator Plants

(Harvested July 8, 1933)

\begin{tabular}{|c|c|c|c|c|c|c|c|c|c|c|c|c|c|c|}
\hline \multirow{2}{*}{ Depth } & \multicolumn{2}{|c|}{$0 \mathrm{~cm} \mathrm{H}_{2} \mathrm{O}$} & \multicolumn{2}{|c|}{$5 \mathrm{~cm} \mathrm{H}_{2} \mathrm{O}$} & \multicolumn{2}{|c|}{$10 \mathrm{~cm} \mathrm{H}_{2} \mathrm{O}$} & \multicolumn{2}{|c|}{$20 \mathrm{~cm} \mathrm{H}_{2} \mathrm{O}$} & \multicolumn{2}{|c|}{$40 \mathrm{~cm} \mathrm{H}_{2} \mathrm{O}$} & \multicolumn{2}{|c|}{$80 \mathrm{~cm} \mathrm{H}_{2} \mathrm{O}$} & \multicolumn{2}{|c|}{$160 \mathrm{~cm} \mathrm{H}_{2} \mathrm{O}$} \\
\hline & Ht. & Wt. & Ht. & Wt. & Ht. & Wt. & Ht. & Wt. & Ht. & Wt. & Ht. & Wt. & Ht. & Wt. \\
\hline \multicolumn{15}{|c|}{$\mathrm{As}_{2} \mathrm{O}_{3}-400$ p.p.m. in moistening solution } \\
\hline inches & $\mathrm{cm}$ & $g m$ & $\mathrm{~cm}$ & $g m$ & $\mathrm{~cm}$ & $g m$ & $\mathrm{~cm}$ & $g m$ & $\mathrm{~cm}$ & $g m$ & $\mathrm{~cm}$ & $g m$ & $\mathrm{~cm}$ & $g m$ \\
\hline $0-4$ & 4 & 0.1 & 0 & 0.0 & 6 & 0.2 & 15 & 1.1 & 17 & 1.6 & 22 & 2.6 & 19 & 2.3 \\
\hline 4-8 & 8 & 0.2 & 0 & 0.0 & 5 & 0.1 & 11 & 0.8 & 16 & 1.7 & 20 & 2.3 & 18 & 1.7 \\
\hline $8-12$ & 10 & 0.5 & 0 & 0.0 & 5 & 0.2 & 9 & 0.5 & 15 & 1.6 & 19 & 1.8 & 19 & 2.0 \\
\hline $12-16$ & 18 & 2.5 & 7 & 0.4 & 5 & 0.2 & 8 & 0.4 & 15 & 1.4 & 18 & 1.9 & 19 & 1.8 \\
\hline $16-20$ & 18 & 3.2 & 12 & 2.0 & 7 & 0.3 & 10 & 0.5 & 18 & 1.9 & 19 & 1.7 & 21 & 2.4 \\
\hline $20-24$ & 19 & 3.4 & 16 & 2.6 & 13 & 1.6 & 9 & 0.6 & 12 & 0.9 & 16 & 1.5 & 21 & 2.3 \\
\hline $24-28$ & 19 & 3.6 & 16 & 3.0 & 17 & 3.3 & 19 & 2.5 & 16 & 1.4 & 18 & 1.9 & 21 & 2.4 \\
\hline $28-32$ & 18 & 2.8 & 14 & 2.8 & 17 & 3.2 & 17 & 2.4 & 18 & 1.7 & 17 & 1.7 & 21 & 2.6 \\
\hline $32-36$ & 17 & 3.3 & 17 & 3.1 & 18 & 3.7 & 16 & 2.4 & 18 & 2.4 & 16 & 1.5 & 20 & 2.2 \\
\hline \multicolumn{15}{|c|}{ Check tubes-moistened with water } \\
\hline inches & $\mathrm{cm}$ & $g m$ & $\mathrm{~cm}$ & $g m$ & $\mathrm{~cm}$ & $g m$ & $\mathrm{~cm}$ & $g m$ & $\mathrm{~cm}$ & $g m$ & $\mathrm{~cm}$ & $g m$ & $\mathrm{~cm}$ & $g m$ \\
\hline $0-4$ & $\ldots$ & $\ldots . .$. & 19 & 2.9 & 20 & 3.1 & $\ldots$. & ......... & 20 & 3.5 & $\ldots$. & ........ & 20 & 3.1 \\
\hline 4-8 & $\ldots$ & $\ldots \ldots$ & 21 & 3.0 & 22 & 3.5 & $\ldots$. & $\ldots . .$. & 20 & 3.1 & $\ldots$. & $\ldots . .$. & 19 & 3.0 \\
\hline $8-12$ & $\ldots$. & $\ldots . . .$. & 21 & 3.0 & 23 & 3.5 & .... & $\ldots \ldots$ & 21 & 3.6 & $\ldots$ & $\ldots \ldots$ & 21 & 3.6 \\
\hline $12-16$ & $\ldots$ & $\ldots \ldots$ & 19 & 3.2 & 22 & 3.6 . & $\ldots$ & $\ldots . .$. & 21 & 3.5 & $\ldots$. & $\ldots . .$. & 21 & 3.7 \\
\hline $16-20$ & $\ldots$ & $\ldots . .$. & 21 & 3.3 & 22 & 3.9 & $\ldots$. & $\ldots . .$. & 22 & 3.9 & $\ldots$ & $\ldots \ldots$ & 21 & 3.6 \\
\hline $20-24$ & $\ldots$. & $\ldots . .$. & 21 & 3.5 & 21 & 3.9 & $\ldots$. & $\ldots . . .$. & 22 & 3.9 & $\ldots$. & $\ldots . .$. & 21 & 3.5 \\
\hline 24-28 & $\ldots$ & $\ldots . .$. & 20 & 3.2 & 23 & 3.8 & $\ldots$ & $\ldots . .$. & 20 & 3.8 & $\ldots$. & $\ldots . .$. & 21 & 3.4 \\
\hline $28-32$ & $\ldots$. & $\ldots . . .$. & 20 & 3.4 & 21 & 3.1 & $\ldots$. & $\ldots . .$. & 18 & 3.6 & $\ldots$ & ....... & 21 & 3.4 \\
\hline $32-36$ & $\ldots$ & $\ldots . .$. & 18 & 3.1 & 22 & 3.2 & $\ldots$. & $\ldots . .$. & 19 & 3.0 & $\ldots$. & $\ldots . .$. & 20 & 3.0 \\
\hline Check* & 19 & 3.6 & 22 & 3.5 & 22 & 4.0 & 22 & 3.7 & 21 & 3.5 & 19 & 2.8 & $\ldots$. & $\ldots . .$. \\
\hline
\end{tabular}

* These checks were cultures in air-dry soil moistened and planted, with no other treatment. Average weight of the $6=3.5$ grams.

tural soils, others may lie even beyond these limits. Only a comprehensive survey will give the complete range of this variance in toxicity. In addition, loss of toxicity varies with time and cropping, and largely determines the permanence of a given application in arid regions. Here again the sandy soils seem favored. Possibly with longer testing these differences will tend to diminish.

Besides soil differences, numerous weed species of varying characteristics are usually found in any given area. Plant species vary in susceptibility to toxic substances; but--more important in soil-sterilization practice-they vary in the character and depth of their root systems. 
As indicated by the soil-tube tests on the fixing and leaching of arsenic in soils, this chemical will be held in the top layers of soil in fairly high concentrations and will remain there even after considerable rainfall. This is highly desirable in the control of annual weeds; but for deeprooted perennials a greater penetration is needed. Here, again, the results of these studies have been confirmed in the field. In the Fresno

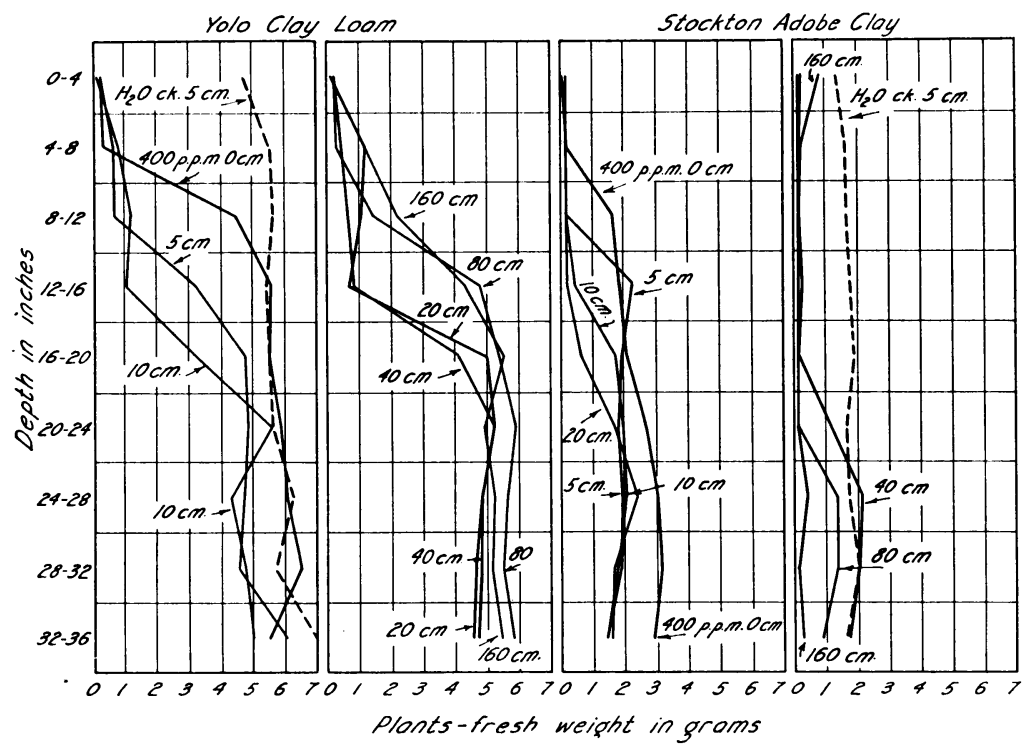

Fig. 9.-The effect of leaching upon the location of sodium arsenite in soil columns as shown by crop yield.

sandy loam, Bermuda grass may be controlled with a sodium arsenite application equivalent to 4 pounds of $\mathrm{As}_{2} \mathrm{O}_{3}$ per square rod. In the Yolo clay loam a similar application controlled annual weeds but not Bermuda grass.

Tests of these sterile soils indicate that the 4-pound application in the Fresno soil penetrated to a depth of 12 inches after a total rainfall of about 5 inches. In the Yolo soil, under similar conditions, the penetration was scarcely more than 2 inches. Though the method of application in the field differs considerably from that used in the soil-tube tests, the low fixing capacity and ready leaching in the Fresno sand, so apparent in these tests, allow considerable penetration in the field and work to an advantage where Bermuda grass is to be controlled.

One further difference between the soil-tube tests and field conditions should be noted. In the leaching tests the flow of water is slow but continuous. In the field the movement of water from rains is not only variable in rate but intermittent. The net effect in regions of fairly low 
rainfall is to give less movement of the toxicant than would be expected on the basis of experiments. Tests conducted in March, 1934, on the location of the arsenic in the soil of plots on Fresno sandy loam that received 4 pounds in January, 1932, show it still to be in the highest concentration in the top 2 inches of soil. Though these plots have received over 40 centimeters of rainfall since the application, they have prob-

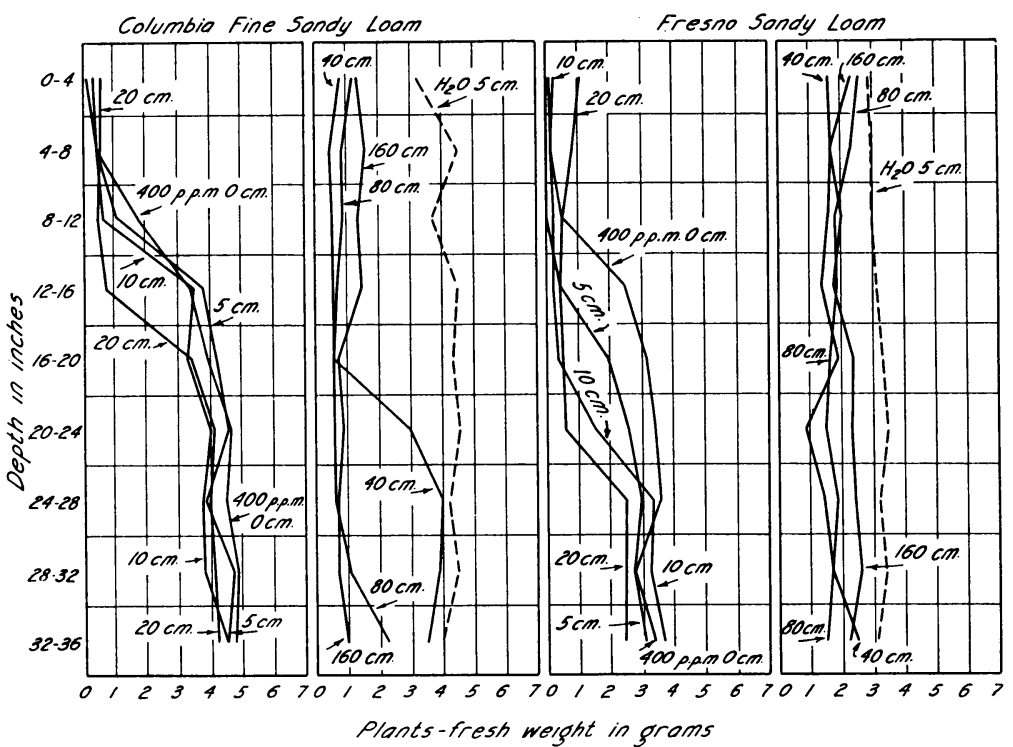

Fig. 10.- The effect of leaching upon the location of sodium arsenite in soil columns as shown by crop yield.

ably never been wet to a greater depth than 4 feet at any one time. In the tube tests the continuous application of 20 surface centimeters of water will wet a column of this soil 40 inches in height; and this continuous flow is the most effective factor in moving the arsenic.

Where light soils occur in regions of heavy rainfall, leaching of the toxicant from the soil would shorten the duration of a given treatment. Possibly this difficulty could be remedied by using arsenic in a less soluble form. The dry arsenic trioxide, though ineffective the first season after application, is apparently equal to an equivalent amount of sodium arsenite during succeeding seasons. This type of treatment may solve the problem where heavy rainfall causes excessive leaching. The question of deep penetration in heavy soils can probably be best answered by using sodium chlorate, a toxicant less firmly fixed and more readily leached than arsenic.

Evidently, therefore, though the results of the experiments with arsenic in soils that have been described are not directly applicable to soil- 
sterilization practice in the field, they afford much useful information and answer many perplexing questions that could be solved by plot tests only after long and tedious work.

\section{STUDIES WITH SODIUM CHLORATE}

Experiments by Åslander ${ }^{(1,2)}$ and Muenscher ${ }^{(11)}$ in New York, by Loomis and his coworkers ${ }^{(9,10)}$ in Iowa, and by the writer $^{(6)}$ in Califor-

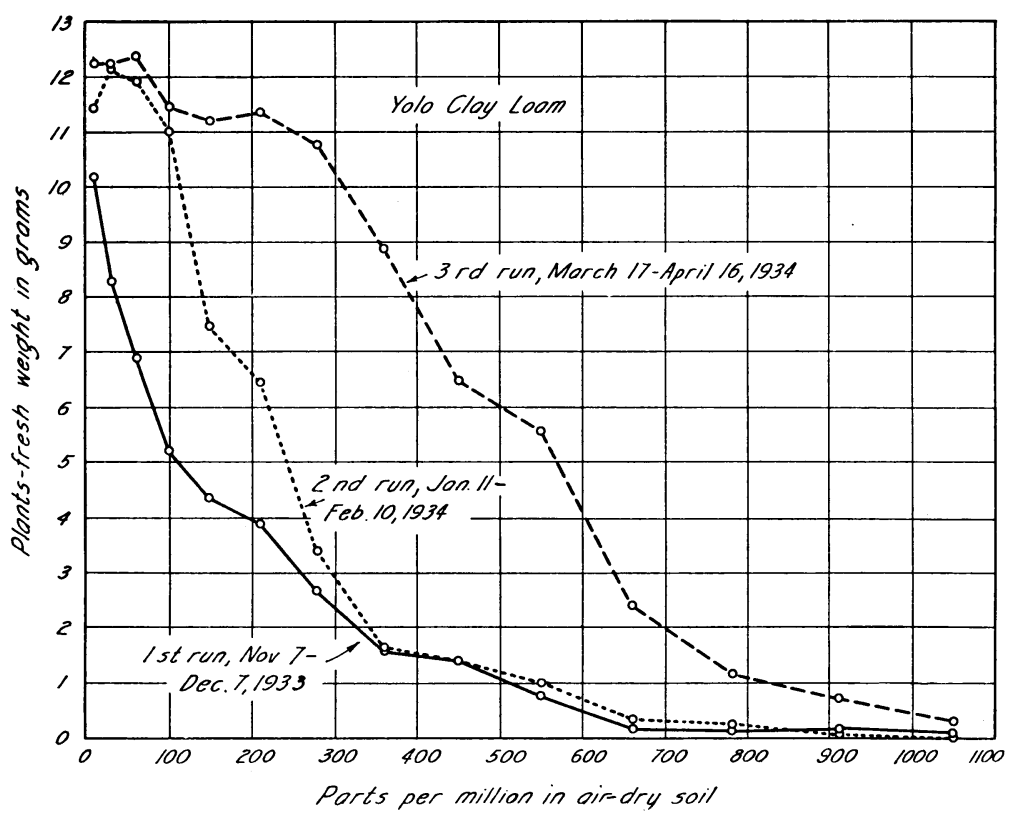

Fig. 11.-The relation of erop yield to the concentration of sodium chlorate in Yolo clay loam.

nia have demonstrated that sodium chlorate is toxic to plants when applied through the soil alone. Regardless of its action through the plant after absorption by foliar parts, it is an effective herbicide when used in the soil; and in arid regions, its toxic effects upon the roots of plants are important in any treatment of deep-rooted perennials. In California the most successful treatments are made just before or during the rainy season so that the chemical is soon carried into the soil, where it kills the roots and rhizomes of the plants and suffers little loss from decomposition.

Considering the importance of this method, as contrasted with the summer spraying so common in the East, a study of the behavior of chlorates in western soils seems desirable. With this in mind, experiments have been conducted to find the relative toxicity of sodium chlo- 


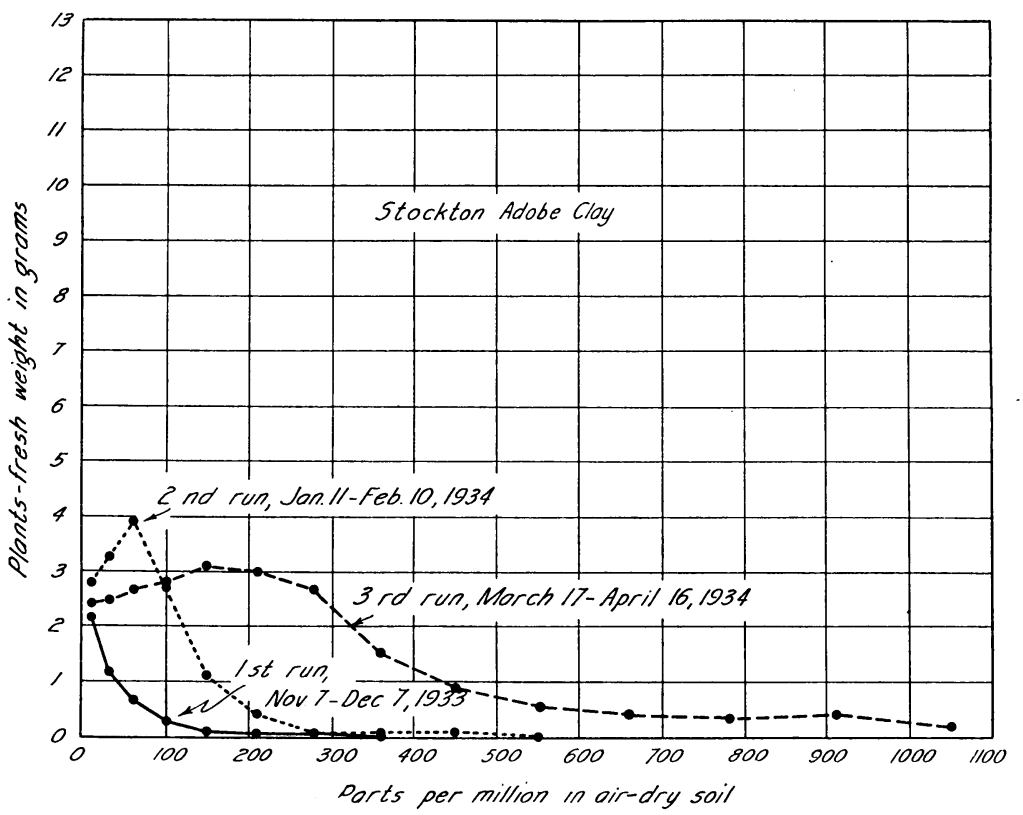

Fig. 12.-The relation of crop yield to the concentration of sodium chlorate in Stockton adobe clay.

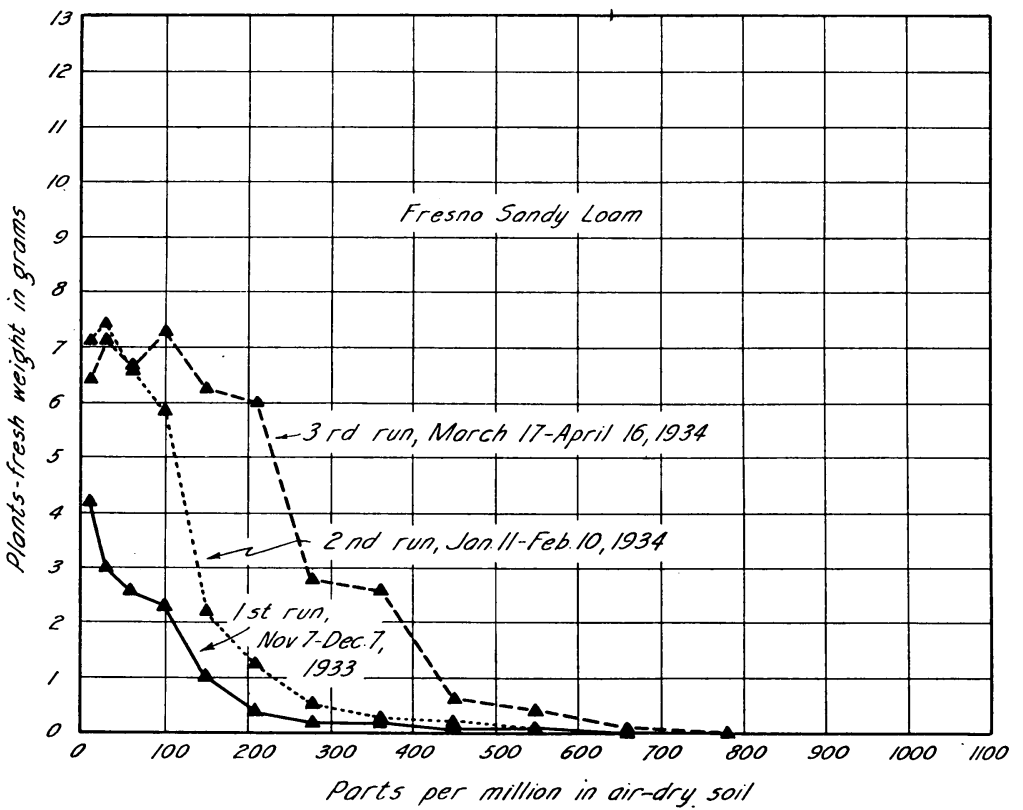

Fig. 13.-The relation of crop yield to the concentration of sodium chlorate in Fresno sandy loam. 
rate in four California soils, the fixing power of these soils for chlorate, and the effects of leaching. The method and soils are essentially the same as those used in the studies with sodium arsenite.

The Toxicity Tests.-During the current season a series having 24 concentrations and 4 checks has been used in studying the toxicity of sodium chlorate. All concentrations and checks were replicated five

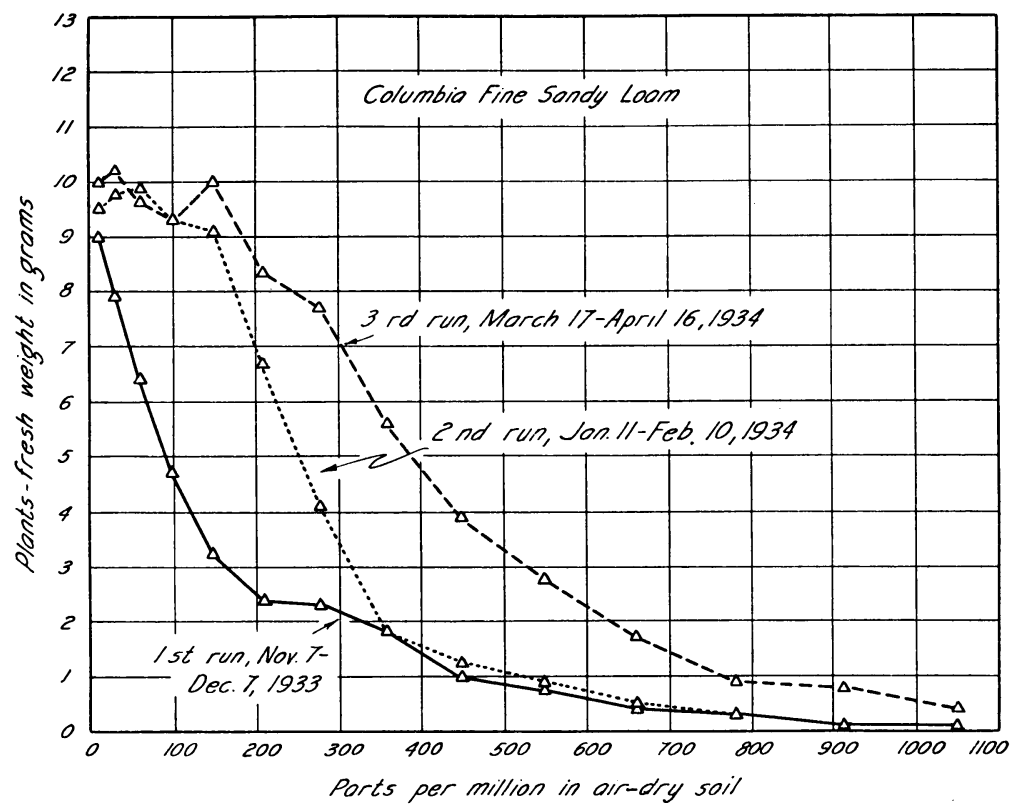

Fig. 14.-The relation of crop yield to the concentration of sodium chlorate in Columbia fine sandy loam.

times. The soils used were Yolo clay loam, Stockton adobe clay, Fresno sandy loam, and Columbia fine sandy loam. The data from the first three runs appear in table 9 and figures $11,12,13$, and 14 . Since all the differences shown in these runs appear within the first 14 concentrations, only these are included in the present report.

In general the data from these tests do not differ greatly from those on arsenic. The same wide differences in crop-producing power of the four soils are in evidence, and the correlation of low crops with high toxicity is somewhat more striking. There seems to be a higher degree of toxicity in the Stockton soil with chlorate than with arsenic, and inversely a lower toxicity in the Fresno soil.

Considering the three runs with chlorate, the third shows the greatest loss of toxicity (table 9 ), probably because of increasing tempera- 


\section{TABLE 9}

Toxicity of Sodium Chlorate in Four California Solls, as Shown by Growth of Indicator Plants

\begin{tabular}{|c|c|c|c|c|c|c|c|c|}
\hline \multirow{2}{*}{$\begin{array}{c}\text { Sodium chlorate } \\
\text { expressed as } \\
\text { p.p.m. } \mathrm{NaClO}_{3} \\
\text { in the } \\
\text { air-dry soil }\end{array}$} & \multicolumn{2}{|c|}{$\begin{array}{l}\text { Yolo clay } \\
\text { loam }\end{array}$} & \multicolumn{2}{|c|}{$\begin{array}{l}\text { Stockton adobe } \\
\text { clay }\end{array}$} & \multicolumn{2}{|c|}{$\begin{array}{c}\text { Fresno sandy } \\
\text { loam }\end{array}$} & \multicolumn{2}{|c|}{$\begin{array}{l}\text { Columbia fine } \\
\text { sandy loam }\end{array}$} \\
\hline & Height & Weight & Height & Weight & Height & Weight & Height & Weight \\
\hline \multicolumn{9}{|c|}{ First run harvested December 7, 1933} \\
\hline $10 \ldots \ldots$ & $\begin{array}{l}c m \\
32\end{array}$ & $\begin{array}{c}g m \\
10.2\end{array}$ & $\begin{array}{c}c m \\
17\end{array}$ & $\begin{array}{l}g m \\
2.2\end{array}$ & $\begin{array}{c}c m \\
28\end{array}$ & $\begin{array}{c}g m \\
4.2\end{array}$ & $\begin{array}{l}c m \\
31\end{array}$ & $\begin{array}{l}g m \\
9.0\end{array}$ \\
\hline . & 32 & 8.3 & 14 & 1.2 & 27 & 3.0 & 31 & 7.9 \\
\hline $60 \ldots$ & 31 & 6.9 & 11 & 0.7 & 24 & 2.6 & 29 & 6.4 \\
\hline 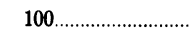 & 29 & 5.2 & 6 & 0.3 & 23 & 2.3 & 28 & 4.7 \\
\hline $150 \ldots \ldots \ldots \ldots$ & 28 & 4.4 & 4 & 0.1 & 15 & 1.0 & 26 & 3.2 \\
\hline $210 \ldots$ & 27 & 3.9 & 3 & 0.1 & 6 & 0.4 & 22 & 2.4 \\
\hline $280 \ldots \ldots$ & 23 & 2.7 & 3 & 0.1 & 4 & 0.2 & 21 & 2.3 \\
\hline 360 & 18 & 1.6 & 0 & 0.0 & 4 & 0.2 & 19 & 1.8 \\
\hline 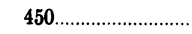 & 17 & 1.4 & 0 & 0.0 & 3 & 0.1 & 13 & 1.0 \\
\hline 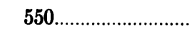 & 12 & 0.8 & 0 & 0.0 & 2 & 0.1 & 9 & 0.7 \\
\hline $660 \ldots \ldots \ldots$ & 4 & 0.2 & 0 & 0.0 & 0 & 0.0 & 6 & 0.4 \\
\hline 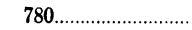 & 4 & 0.2 & 0 & 0.0 & 0 & 0.0 & 5 & 0.3 \\
\hline $940 \ldots$ & 4 & 0.2 & 0 & 0.0 & 0 & 0.0 & 2 & 0.1 \\
\hline $1,050 \ldots$ & 2 & 0.1 & 0 & 0.0 & 0 & 0.0 & 2 & 0.1 \\
\hline Check .................. & 31 & 11.1 & 17 & 2.3 & 29 & 6.0 & 30 & 9.2 \\
\hline \multicolumn{9}{|c|}{ Second run harvested February 10,1934} \\
\hline & $\mathrm{cm}$ & $g m$ & $\mathrm{~cm}$ & $g m$ & $\mathrm{~cm}$ & $g m$ & $\mathrm{~cm}$ & $g m$ \\
\hline . & 35 & 8.2 & 20 & 2.3 & 26 & 4.5 & 30 & 7.5 \\
\hline $30 \ldots$ & 35 & 8.7 & 21 & 2.7 & 29 & 4.7 & 30 & 7.8 \\
\hline $60 \ldots$ & 34 & 8.5 & 24 & 3.2 & 28 & 4.2 & 31 & 7.9 \\
\hline 100 & 33 & 7.8 & 21 & 2.2 & 16 & 3.7 & 30 & 7.4 \\
\hline $150 \ldots \ldots \ldots \ldots \ldots$ & 30 & 5.3 & 14 & 0.9 & 17 & 1.4 & 29 & 7.2 \\
\hline $210 \ldots \ldots \ldots \ldots \ldots \ldots \ldots \ldots \ldots$ & 28 & 4.6 & 10 & 0.3 & 18 & 0.8 & 28 & 5.3 \\
\hline 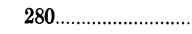 & 24 & 2.4 & 7 & 0.1 & 9 & 0.3 & 24 & 3.3 \\
\hline $360 \ldots$ & 16 & 1.2 & 6 & 0.1 & 7 & 0.2 & 19 & 1.4 \\
\hline 450 & 16 & 1.0 & 4 & 0.1 & 6 & 0.1 & 16 & 1.0 \\
\hline $550 \ldots \ldots \ldots \ldots$ & 14 & 0.7 & 0 & 0.0 & 0 & 0.0 & 14 & 0.7 \\
\hline 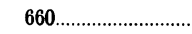 & 11 & 0.3 & 0 & 0.0 & 0 & 0.0 & 12 & 0.4 \\
\hline $780 \ldots \ldots \ldots \ldots \ldots \ldots \ldots \ldots \ldots \ldots \ldots \ldots \ldots$ & 7 & 0.2 & 0 & 0.0 & 0 & 0.0 & 9 & 0.2 \\
\hline 940 & 5 & 0.1 & 0 & 0.0 & 0 & 0.0 & 7 & 0.1 \\
\hline $1,050 \ldots \ldots$ & 0 & 0.0 & 0 & 0.0 & 0 & 0.0 & 0 & 0.0 \\
\hline Check........................ & 33 & 7.9 & 18 & 1.9 & 24 & 3.8 & 30 & 7.3 \\
\hline \multicolumn{9}{|c|}{ Third run harvested April 16, 1934} \\
\hline & $\mathrm{cm}$ & $g m$ & $\mathrm{~cm}$ & $g m$ & cm & $g m$ & cm & $g m$ \\
\hline 10 & 33 & 8.3 & 24 & 3.5 & 33 & 5.4 & 34 & 7.6 \\
\hline $30 \ldots$ & 33 & 8.3 & 25 & 3.6 & 32 & 6.0 & 34 & 7.8 \\
\hline $60 \ldots$ & 34 & 8.4 & 26 & 4.0 & 32 & 5.7 & 32 & 7.3 \\
\hline $100 \ldots \ldots \ldots \ldots$ & 34 & 7.8 & 26 & 4.2 & 32 & 6.2 & 34 & 7.1 \\
\hline $150 \ldots$ & 34 & 7.6 & 29 & 4.6 & 32 & 5.3 & 35 & 7.6 \\
\hline $210 \ldots \ldots \ldots \ldots$ & 34 & 7.7 & 28 & 4.4 & 31. & 5.1 & 34 & 6.3 \\
\hline $280 \ldots$ & 34 & 7.3 & 26 & 4.0 & 24 & 2.4 & 33 & 5.9 \\
\hline $360 \ldots \ldots \ldots \ldots \ldots$ & 31 & 6.0 & 19 & 2.2 & 22 & 2.2 & 29 & 4.3 \\
\hline $450 \ldots \ldots \ldots \ldots \ldots$ & 30 & 4.4 & 19 & 1.9 & 10 & 0.5 & 24 & 3.0 \\
\hline $550 \ldots$ & 27 & 3.8 & 9 & 0.9 & 8 & 0.3 & 20 & 2.1 \\
\hline $660 \ldots \ldots \ldots \ldots \ldots \ldots$ & 16 & 1.6 & 9 & 0.6 & 5 & 0.1 & 16 & 1.3 \\
\hline $780 \ldots \ldots \ldots \ldots$ & 13 & 0.8 & 8 & 0.4 & 0 & 0.0 & 11 & 0.7 \\
\hline $940 \ldots \ldots$ & 9 & 0.5 & 10 & 0.6 & 0 & 0.0 & 9 & 0.6 \\
\hline $1,050 \ldots \ldots \ldots \ldots \ldots \ldots \ldots \ldots \ldots \ldots$ & 7 & 0.2 & 7 & 0.3 & 0 & 0.0 & 6 & 0.3 \\
\hline Check & 30 & 7.5 & 23 & 3.4 & 30 & 5.1 & 32 & 7.0 \\
\hline
\end{tabular}


ture with the advance of the season. As the Iowa workers ${ }^{(10)}$ have shown, chlorate decomposition is greater as temperatures are raised.

The Soil-Tube Tests.-The fixing power of the four soils is much less for chlorate than for arsenic. Since preliminary tests had indicated this

TABLE 10

Effect of Rate of Wetting upon Chlorate Fixation by Yolo Clay Loam and Fresno Sandy Loam, as Shown by Growth of Indicator Plants

\begin{tabular}{|c|c|c|c|c|c|c|c|c|c|c|c|c|c|}
\hline \multirow{3}{*}{ Soil type } & \multirow{3}{*}{ Depth } & \multirow{2}{*}{\multicolumn{2}{|c|}{$\begin{array}{l}\mathrm{H}_{2} \mathrm{O} \text { check } \\
12 \text { d.p.m.* }\end{array}$}} & \multicolumn{10}{|c|}{$\mathrm{NaClO}_{3}-200$ p.p.m. } \\
\hline & & & & \multicolumn{2}{|c|}{20 d.p.m.* } & \multicolumn{2}{|c|}{15 d.p.m.* } & \multicolumn{2}{|c|}{12 d.p.m.* } & \multicolumn{2}{|c|}{10 d.p.m.* } & \multicolumn{2}{|c|}{6 d.p.m.* } \\
\hline & & Ht. & Wt. & Ht. & Wt. & Ht. & Wt. & Ht. & Wt. & Ht. & Wt. & Ht. & Wt. \\
\hline \multirow{11}{*}{$\begin{array}{l}\text { Yolo clay } \\
\text { loam; } \\
\text { harvested } \\
\text { Jan. 20, } \\
1934\end{array}$} & inches & $\mathrm{cm}$ & $g m$ & $\mathrm{~cm}$ & $g m$ & $\mathrm{~cm}$ & $g m$ & $\mathrm{~cm}$ & $g m$ & $\mathrm{~cm}$ & $g m$ & $\mathrm{~cm}$ & $g m$ \\
\hline & $0.0-3.6$ & 26 & 4.5 & 14 & 1.0 & 18 & 1.5 & 14 & 1.1 & 14 & 1.0 & 17 & 1.0 \\
\hline & $3.6-7.2$ & 24 & 4.1 & 16 & 1.0 & 9 & 0.6 & 16 & 1.2 & 16 & 0.9 & 11 & 0.7 \\
\hline & $7.2-10.8$ & 25 & 4.7 & 16 & 2.0 & 12 & 0.9 & 13 & 1.0 & 12 & 0.9 & 10 & 0.4 \\
\hline & $10.8-14.4$ & 27 & 5.5 & 12 & 1.0 & 7 & 0.3 & 11 & 0.7 & 15 & 0.7 & 15 & 0.9 \\
\hline & $\{14.4-18.0$ & 25 & 5.3 & 9 & 0.5 & 8 & 0.3 & 13 & 1.1 & 22 & 1.5 & 19 & 2.2 \\
\hline & $18.0-21.6$ & 25 & 5.7 & 10 & 0.9 & 12 & 0.6 & 17 & 2.0 & 22 & 3.3 & 28 & 6.6 \\
\hline & $21.6-25.2$ & 31 & 7.7 & 11 & 1.5 & 9 & 0.6 & 29 & 7.1 & 32 & 7.3 & 32 & 6.7 \\
\hline & 25. $2-28.8$ & 32 & 7.6 & 29 & 6.9 & 30 & 6.9 & 32 & 8.0 & 32 & 7.5 & 36 & 7.3 \\
\hline & $28.8-32.4$ & 30 & 6.1 & 29 & 6.5 & 28 & 4.8 & 28 & 5.8 & 31 & 5.4 & 28 & 5.6 \\
\hline & $(32.4-36.0$ & 30 & 5.9 & 28 & 6.1 & 29 & 5.2 & 28 & 5.4 & 29 & 5.5 & 28 & 5.6 \\
\hline \multirow{10}{*}{$\begin{array}{l}\text { Fresno } \\
\text { sandy } \\
\text { loam; } \\
\text { harvested } \\
\text { Jan. 20, } \\
1934\end{array}$} & $0.0-3.6$ & 19 & 2.7 & 6 & 0.1 & 5 & 0.1 & 6 & 0.2 & 8 & 0.2 & 6 & 0.3 \\
\hline & $3.6-7.2$ & 19 & 2.8 & 7 & 0.4 & 10 & 0.4 & 8 & 0.4 & 12 & 0.6 & 12 & 0.7 \\
\hline & $7.2-10.8$ & 21 & 3.2 & 10 & 0.6 & 13 & 0.7 & 10 & 0.5 & 6 & 0.3 & 6 & 0.3 \\
\hline & $10.8-14.4$ & 21 & 3.3 & 11 & 0.5 & 9 & 0.5 & 6 & 0.2 & 8 & 0.4 & 11 & 0.6 \\
\hline & $\{14.4-18.0$ & 23 & 3.9 & 10 & 0.7 & 13 & 0.9 & 9 & 0.5 & 9 & 0.4 & 8 & 0.4 \\
\hline & $18.0-21.6$ & 21 & 3.1 & 11 & 0.7 & 13 & 0.6 & 7 & 0.3 & 9 & 0.4 & 11 & 0.7 \\
\hline & $21.6-25.2$ & 22 & 3.6 & 11 & 0.6 & 13 & 0.7 & 9 & 0.5 & 14 & 1.1 & 15 & 0.9 \\
\hline & $25.2-28.8$ & 24 & 3.8 & 9 & 0.6 & 12 & 0.7 & 13 & 0.7 & 11 & 0.6 & 15 & 0.9 \\
\hline & $28.8-32.4$ & 26 & 4.6 & 14 & 1.0 & 15 & 0.8 & 10 & 0.8 & 16 & 1.5 & 17 & 1.0 \\
\hline & (32.4-36.0 & 30 & 7.1 & 25 & 4.3 & 26 & 4.8 & 25 & 4.5 & 29 & 6.0 & 27 & 4.7 \\
\hline
\end{tabular}

"In this table, "d.p.m." means drops per minute.

fact and since with low fixing power the rate of wetting of the soil columns might be a factor, an experiment was designed to clarify this point. The resultant data are given in table 10 and in figure 15. In Yolo clay loam, evidently, rate of wetting is important. More chlorate is taken from the solution at the lower rate of moistening, and the depth of penetration decreases. In the Fresno soil there were no differences.

In the practical problem of conducting these experiments, there are certain limits upon the method. The heavier soils cannot be moistened evenly at a rate much above 12 drops per minute from the tips used in these experiments. On the other hand, lowering the rate prolongs the process until it becomes tedious. This rate of 12 drops per minute was used in the following tests (tables 11 to 15) as in the arsenic studies. In considering the data being presented, one must remember that, had the 


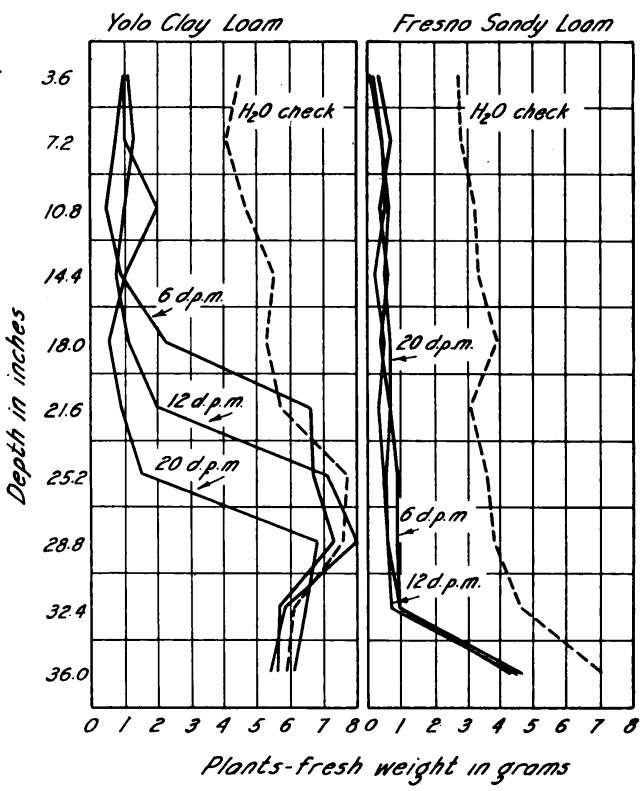

Fig. 15.-The effect of rate of wetting upon the location of sodium chlorate in soil columns as shown by crop yield. In this figure, "d.p.m." means drops per minute from standard tips.

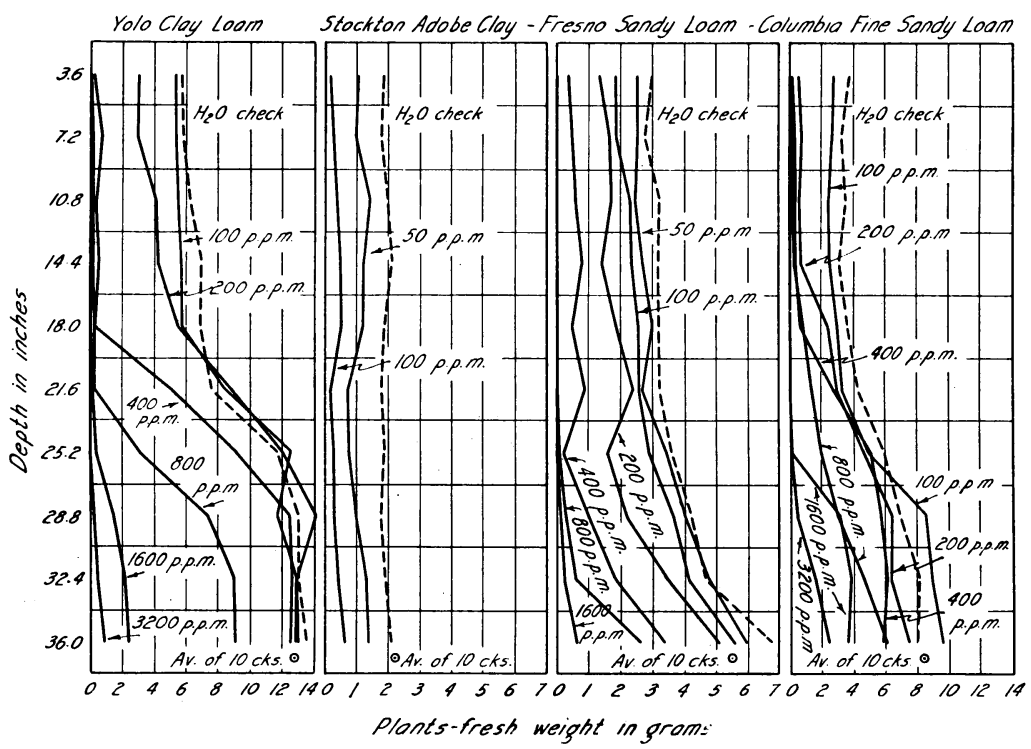

Fig. 16.-The relation of crop yield to penetration of sodium ehlorate into columns of four California soils, showing their fixing power. Crops on the Yolo and Columbia soils were heavy and the scale had to be altered accordingly. 
rate been slower, the fixing would have been somewhat greater in the Yolo and Columbia soils. Where the fixing is stronger, as with arsenic, the rate of moistening is less important.

Data on the fixing of chlorate in the four soils are presented in tables $11,12,13$, and 14 , and in figure 16 . The method was changed slightly in

TABLE 11

The Fixing Power of Yolo Clay Loam for Sodium Chlorate, as Shown by Growth of Indicator Plants*

(Harvested February 25, 1934)

\begin{tabular}{|c|c|c|c|c|c|c|c|c|c|c|}
\hline \multirow{2}{*}{ Depth } & \multicolumn{2}{|c|}{$\begin{array}{l}\mathrm{H}_{2} \mathrm{O} \\
\text { check }\end{array}$} & \multicolumn{2}{|c|}{$\begin{array}{c}\mathrm{NaClO}_{3} \\
100 \text { p.p.m. }\end{array}$} & \multicolumn{2}{|c|}{$\begin{array}{c}\mathrm{NaClO}_{3} \\
200 \text { p.p.m. }\end{array}$} & \multicolumn{2}{|c|}{$\underset{400 \text { p.p.m. }}{\mathrm{NaClO}_{3}}$} & \multicolumn{2}{|c|}{$\begin{array}{c}\mathrm{NaClO}_{3} \\
800 \text { p.p.m. }\end{array}$} \\
\hline & Ht. & Wt. & Ht. & Wt. & Ht. & Wt. & Ht. & Wt. & Ht. & Wt. \\
\hline inches & $\mathrm{cm}$ & $g m$ & $\mathrm{~cm}$ & $g m$ & $\mathrm{~cm}$ & $g m$ & $\mathrm{~cm}$ & $g m$ & $\mathrm{~cm}$ & $g m$ \\
\hline $0.0-3.6$ & 24 & 5.6 & 25 & 5.3 & 24 & 2.9 & 8 & 0.2 & 0 & 0.0 \\
\hline $3.6-7.2$ & 23 & 5.8 & 25 & 5.3 & 26 & 2.8 & 18 & 0.6 & 5 & 0.1 \\
\hline $7.2-10.8$ & 24 & 6.3 & 24 & 5.4 & 26 & 3.1 & 8 & 0.2 & 5 & 0.1 \\
\hline $10.8-14.4$ & 25 & 6.9 & 25 & 5.6 & 27 & 3.2 & 13 & 0.4 & 5 & 0.1 \\
\hline $14.4-18.0$ & 27 & 6.8 & 26 & 5.8 & 28 & 5.6 & 8 & 0.2 & 10 & 0.2 \\
\hline $18.0-21.6$ & 28 & 7.7 & 27 & 8.5 & 29 & 8.8 & 28 & 5.1 & 8 & 0.2 \\
\hline $21.6-25.2$ & 30 & 11.8 & 27 & 12.6 & 29 & 12.1 & 32 & 9.2 & 24 & 3.1 \\
\hline $25.2-28.8$ & 30 & 13.0 & 27 & 11.8 & 30 & 14.2 & 32 & 12.4 & 32 & 7.4 \\
\hline $28.8-32.4$ & 30 & 13.0 & 29 & 12.9 & 31 & 13.0 & 32 & 12.6 & 36 & 8.7 \\
\hline $32.4-36.0$ & 32 & 13.5 & 30 & 13.0 & 31 & 12.9 & 31 & 12.4 & 36 & 9.0 \\
\hline \multirow{2}{*}{ Depth } & \multicolumn{2}{|c|}{$\underset{1,600 \text { p.p.m. }}{\mathrm{NaClO}_{3}}$} & \multicolumn{2}{|c|}{$\begin{array}{c}\mathrm{NaClO}_{3} \\
\text { 3,200 p.p.m. }\end{array}$} & \multicolumn{2}{|c|}{$\begin{array}{c}\mathrm{NaClO}_{3} \dagger \\
100 \text { p.p.m. }\end{array}$} & \multicolumn{2}{|c|}{$\begin{array}{c}\mathrm{NaClO}_{3} \dagger \\
400 \text { p.p.m. }\end{array}$} & \multicolumn{2}{|c|}{$\begin{array}{c}\mathrm{NaClO}_{3} \dagger \\
1,600 \text { p.p.m. }\end{array}$} \\
\hline & Ht. & Wt. & Ht. & Wt. & Ht. & Wt. & Ht. & Wt. & Ht. & Wt. \\
\hline inches & $\mathrm{cm}$ & $g m$ & $\mathrm{~cm}$ & $g m$ & $\mathrm{~cm}$ & $g m$ & $\mathrm{~cm}$ & $g m$ & $\mathrm{~cm}$ & $g m$ \\
\hline $0.0-3.6$ & 0 & 0.0 & 0 & 0.0 & 25 & 3.5 & $\mathbf{0}$ & 0.0 & 0 & 0.0 \\
\hline $3.6-7.2$ & 0 & 0.0 & 0 & 0.0 & 26 & 3.8 & 6 & 0.1 & $\mathbf{0}$ & 0.0 \\
\hline $7.2-10.8$ & 0 & 0.0 & 0 & 0.0 & 26 & 4.0 & 7 & 0.1 & 0 & 0.0 \\
\hline $10.8-14.4$ & 0 & 0.0 & 0 & 0.0 & 27 & 4.0 & 6 & 0.1 & 0 & 0.0 \\
\hline $14.4-18.0$ & 0 & 0.0 & 0 & 0.0 & 25 & 3.6 & 7 & 0.1 & 0 & 0.0 \\
\hline $18.0-21.6$ & 5 & 0.1 & 0 & 0.0 & 24 & 4.6 & 7 & 0.1 & $\mathbf{0}$ & 0.0 \\
\hline $21.6-25.2$ & 8 & 0.2 & 0 & 0.0 & 27 & 4.4 & 7 & 0.2 & 0 & 0.0 \\
\hline $25.2-28.8$ & 16 & 1.6 & 6 & 0.2 & 27 & 4.1 & 10 & 0.4 & 0 & 0.0 \\
\hline $28.8-32.4$ & 29 & 2.2 & 7 & 0.3 & 27 & 4.4 & 15 & 0.9 & 6 & 0.2 \\
\hline $32.4-36.0$ & 30 & 2.3 & 14 & 0.8 & 28 & 4.6 & 17 & 1.0 & 6 & 0.2 \\
\hline
\end{tabular}

* Average weight of plants in 10 untreated checks $=12.7$ grams.

+ The soil in the last three tubes was moistened before the sodium chlorate was applied. All other applications were to dry soil.

running these and subsequent soil-tube tests. In all previous tests the soil was measured into the cans by weight in fractionating the column. In some tubes certain fractions proved somewhat more moist than others, even after 24 to 48 hours had been allowed for the moisture to reach equilibrium. These moist fractions would contain less soil when placed in the cans and with the method of watering used would remain more moist throughout the experiment. Trials showed that fractiona- 
tion into columns of equal height not only was quicker but resulted in a more uniform moisture condition in the various fractions. This method was adopted, the 36 -inch column being divided into ten equal fractions,

TABLE 12

The Fixing Power of Stockton Adobe Clay for Sodium Chlorate, as Shown by Growth of Indicator Plants*

(Harvested March 16, 1934)

\begin{tabular}{|c|c|c|c|c|c|c|c|c|c|c|}
\hline \multirow{2}{*}{ Depth } & \multicolumn{2}{|c|}{$\underset{\text { check }}{\mathrm{H}_{2} \mathrm{O}}$} & \multicolumn{2}{|c|}{$\begin{array}{c}\mathrm{NaClO}_{3} \\
50 \text { p.p.m. }\end{array}$} & \multicolumn{2}{|c|}{$\begin{array}{c}\mathrm{NaClO}_{3} \\
100 \text { p.p.m. }\end{array}$} & \multicolumn{2}{|c|}{$\begin{array}{c}\mathrm{NaClO}_{3} \\
200 \text { p.p.m. }\end{array}$} & \multicolumn{2}{|c|}{$\begin{array}{c}\mathrm{NaClO}_{3} \\
400 \text { p.p.m. }\end{array}$} \\
\hline & Ht. & Wt. & Ht. & Wt. & Ht. & Wt. & Ht. & Wt. & Ht. & Wt. \\
\hline inches & $\mathrm{cm}$ & $g m$ & $\mathrm{~cm}$ & $g m$ & $\mathrm{~cm}$ & $g m$ & $c m$ & $g m$ & $\mathrm{~cm}$ & $g m$ \\
\hline $0.0-3.6$ & 16 & 1.9 & 11 & 1.1 & 8 & 0.2 & 0 & 0.0 & 0 & 0.0 \\
\hline $3.6-7.2$ & 16 & 1.8 & 12 & 1.0 & 8 & 0.3 & 6 & 0.1 & 0 & 0.0 \\
\hline $7.2-10.8$ & 17 & 2.0 & 15 & 1.4 & 8 & 0.4 & 0 & 0.0 & 0 & 0.0 \\
\hline $10.8-14.4$ & 17 & 2.1 & 12 & 1.2 & 9 & 0.5 & 0 & 0.0 & 0 & 0.0 \\
\hline $14.4-18.0$ & 18 & 1.9 & 13 & 1.2 & 9 & 0.5 & 0 & 0.0 & 0 & 0.0 \\
\hline $18.0-21.6$ & 16 & 1.8 & 11 & 0.8 & 6 & 0.2 & 0 & 0.0 & 0 & 0.0 \\
\hline $21.6-25.2$ & 16 & 1.9 & 11 & 0.8 & 8 & 0.3 & 0 & 0.0 & 0 & 0.0 \\
\hline $25.2-28.8$ & 17 & 1.8 & 12 & 1.0 & 8 & 0.3 & 0 & 0.0 & 0 & 0.0 \\
\hline $28.8-32.4$ & 17 & 1.9 & 13 & 1.3 & 8 & 0.4 & 0 & 0.0 & 0 & 0.0 \\
\hline $32.4-36.0$ & 19 & 2.1 & 14 & 1.3 & 10 & 0.7 & 0 & 0.0 & 0 & 0.0 \\
\hline \multirow{2}{*}{ Depth } & \multicolumn{2}{|c|}{$\begin{array}{c}\mathrm{NaClO}_{3} \\
800 \text { p.p.m. }\end{array}$} & \multicolumn{2}{|c|}{$\begin{array}{c}\mathrm{NaClO}_{3} \\
\text { 1,600 p.p.m. }\end{array}$} & \multicolumn{2}{|c|}{$\begin{array}{c}\mathrm{NaClO}_{3} \dagger \\
100 \text { p.p.m. }\end{array}$} & \multicolumn{2}{|c|}{$\begin{array}{c}\mathrm{NaClO}_{3} \dagger \\
400 \text { p.p.m. }\end{array}$} & \multicolumn{2}{|c|}{$\begin{array}{c}\mathrm{NaClO}_{3} \dagger \\
\text { 1,600 p.p.m. }\end{array}$} \\
\hline & Ht. & Wt. & Ht. & Wt. & Ht. & Wt. & Ht. & Wt. & Ht. & Wt. \\
\hline inches & $\mathrm{cm}$ & $g m$ & $\mathrm{~cm}$ & $g m$ & $\mathrm{~cm}$ & $g m$ & $\mathrm{~cm}$ & $g m$ & $\mathrm{~cm}$ & $g m$ \\
\hline $0.0-3.6$ & 0 & 0.0 & 0 & 0.0 & 10 & 0.7 & 0 & 0.0 & 0 & 0.0 \\
\hline $3.6-7.2$ & 0 & 0.0 & 0 & 0.0 & 8 & 0.4 & 0 & 0.0 & 0 & 0.0 \\
\hline $7.2-10.8$ & 0 & 0.0 & 0 & 0.0 & 7 & 0.2 & 0 & 0.0 & 0 & 0.0 \\
\hline $10.8-14.4$ & 0 & 0.0 & 0 & 0.0 & 7 & 0.4 & 0 & 0.0 & 0 & 0.0 \\
\hline $14.4-18.0$ & 0 & 0.0 & 0 & 0.0 & 5 & 0.2 & 0 & 0.0 & 0 & 0.0 \\
\hline $18.0-21.6$ & 0 & 0.0 & 0 & 0.0 & 9 & 0.4 & 0 & 0.0 & 0 & 0.0 \\
\hline $21.6-25.2$ & 0 & 0.0 & 0 & 0.0 & 7 & 0.3 & 0 & 0.0 & 0 & 0.0 \\
\hline $25.2-28.8$ & 0 & 0.0 & 0 & 0.0 & 10 & 0.6 & 0 & 0.0 & 0 & 0.0 \\
\hline $28.8-32.4$ & 0 & 0.0 & 0 & 0.0 & 8 & 0.6 & 0 & 0.0 & 0 & 0.0 \\
\hline $32.4-36.0$ & 0 & 0.0 & 0 & 0.0 & 9 & 0.5 & 0 & 0.0 & 0 & 0.0 \\
\hline
\end{tabular}

* Average weight of 10 untreated checks $=2.2$ grams.

t The soil in the last three tubes was moistened before the sodium chlorate was applied. All other applications were to dry soil.

each containing, theoretically, the weight of soil used in the other experiments.

In the tests on fixing power, ten tubes were used with each soil. The first was simply moistened with distilled water to show the effect upon readily soluble nutrients. Six dry columns of each soil were moistened with chlorate solutions of various concentrations, as indicated in tables 11 to 14 . Three columns of each were moistened with distilled water, and then an equal volume of chlorate solution was applied in the same way, the object being to displace the original moisture with its dissolved nutrients and bring out the effect of chloratie solution alone. 
As results with the dry tubes (fig. 16) show, chlorate is much less firmly fixed in these soils than is arsenic (fig. 8). In the Yolo and Columbia soils chlorate is held mostly within the upper halves of the col-

TABLE 13

The Fixing Power of Fresno Sandy Loam for Sodium Chlorate, as SHown BY Growth of INDiCator Plants* (Harvested March 2, 1934)

\begin{tabular}{|c|c|c|c|c|c|c|c|c|c|c|}
\hline \multirow{2}{*}{ Depth } & \multicolumn{2}{|c|}{$\underset{\text { check }}{\mathrm{H}_{2} \mathrm{O}}$} & \multicolumn{2}{|c|}{$\begin{array}{c}\mathrm{NaClO}_{3} \\
50 \text { p.p.m. }\end{array}$} & \multicolumn{2}{|c|}{$\begin{array}{c}\mathrm{NaClO}_{3} \\
100 \text { p.p.m. }\end{array}$} & \multicolumn{2}{|c|}{$\begin{array}{c}\mathrm{NaClO}_{3} \\
200 \text { p.p.m. }\end{array}$} & \multicolumn{2}{|c|}{$\begin{array}{c}\mathrm{NaClO}_{3} \\
400 \text { p.p.m. }\end{array}$} \\
\hline & Ht. & Wt. & Ht. & Wt. & Ht. & Wt. & Ht. & Wt. & Ht. & Wt. \\
\hline inches & $\mathrm{cm}$ & $g m$ & $\mathrm{~cm}$ & $g m$ & $\mathrm{~cm}$ & $g m$ & $\mathrm{~cm}$ & $g m$ & $\mathrm{~cm}$ & $g m$ \\
\hline $0.0-3.6$ & 25 & 3.0 & 21 & 2.5 & 21 & 1.9 & 19 & 1.3 & 7 & 0.3 \\
\hline $3.6-7.2$ & 21 & 2.8 & 20 & 2.5 & 19 & 1.9 & 22 & 1.7 & 11 & 0.5 \\
\hline $7.2-10.8$ & 22 & 3.2 & 21 & 2.4 & 23 & 2.3 & 21 & 1.7 & 10 & 0.6 \\
\hline $10.8-14.4$ & 20 & 3.2 & 24 & 2.7 & 23 & 2.3 & 20 & 1.4 & 12 & 0.8 \\
\hline $14.4-18.0$ & 21 & 3.2 & 24 & 3.0 & 23 & 2.5 & 21 & 1.9 & 9 & 0.4 \\
\hline $18.0-21.6$ & 23 & 3.2 & 21 & 2.7 & 23 & 2.5 & 22 & 2.4 & 13 & 0.9 \\
\hline $21.6-25.2$ & 25 & 3.6 & 23 & 3.4 & 24 & 2.9 & 21 & 1.6 & 7 & 0.2 \\
\hline $25.2-28.8$ & 23 & 4.2 & 26 & 4.0 & 26 & 3.6 & 22 & 2.2 & 11 & 1.0 \\
\hline $28.8-32.4$ & 26 & 4.7 & 27 & 4.8 & 27 & 4.1 & 26 & 3.5 & 22 & 1.9 \\
\hline $32.4-36.0$ & 28 & 6.8 & 30 & 6.0 & 28 & 5.6 & 29 & 5.1 & 27 & 3.4 \\
\hline \multirow{2}{*}{ Depth } & \multicolumn{2}{|c|}{$\begin{array}{l}\mathrm{NaClO}_{3} \\
800 \text { p.p.m. }\end{array}$} & \multicolumn{2}{|c|}{$\begin{array}{c}\mathrm{NaClO}_{3} \\
\text { 1,600 p.p.m. }\end{array}$} & \multicolumn{2}{|c|}{$\begin{array}{c}\mathrm{NaClO}_{3} \dagger \\
50 \text { p.p.m. }\end{array}$} & \multicolumn{2}{|c|}{$\begin{array}{c}\mathrm{NaClO}_{3} \dagger \\
200 \text { p.p.m. }\end{array}$} & \multicolumn{2}{|c|}{$\begin{array}{c}\mathrm{NaClO}_{3} \dagger \\
800 \text { p.p.m. }\end{array}$} \\
\hline & Ht. & Wt. & Ht. & Wt. & Ht. & Wt. & Ht. & Wt. & Ht. & Wt. \\
\hline inches & $\mathrm{cm}$ & $g m$ & $\mathrm{~cm}$ & $g m$ & $\mathrm{~cm}$ & $g m$ & $\mathrm{~cm}$ & $g m$ & $\mathrm{~cm}$ & $g m$ \\
\hline $0.0-3.6$ & 0 & 0.0 & 0 & 0.0 & 19 & 2.0 & 12 & 0.7 & 0 & 0.0 \\
\hline $3.6-7.2$ & 0 & 0.0 & 0 & 0.0 & 17 & 2.0 & 21 & 1.3 & 0 & 0.0 \\
\hline $7.2-10.8$ & 0 & 0.0 & 0 & 0.0 & 18 & 2.1 & 14 & 0.9 & 5 & 0.1 \\
\hline $10.8-14.4$ & 0 & 0.0 & 0 & 0.0 & 19 & 2.0 & 16 & 1.0 & 5 & 0.1 \\
\hline $14.4-18.0$ & 0 & 0.0 & 0 & 0.0 & 20 & 2.1 & 20 & 1.2 & 5 & 0.1 \\
\hline 18. $0-21.6$ & 0 & 0.0 & 0 & 0.0 & 21 & 2.4 & 10 & 0.9 & 5 & 0.1 \\
\hline $21.6-25.2$ & 4 & 0.1 & 0 & 0.0 & 21 & 2.4 & 20 & 1.4 & 0 & 0.0 \\
\hline $25.2-28.8$ & 5 & 0.2 & 5 & 0.1 & 23 & 2.7 & 18 & 1.4 & 5 & 0.1 \\
\hline $28.8-32.4$ & 10 & 0.6 & 5 & 0.2 & 22 & 2.5 & 17 & 1.0 & 6 & 0.1 \\
\hline $32.4-36.0$ & 29 & 2.7 & 12 & 0.7 & 24 & 2.9 & 19 & 1.5 & 6 & 0.1 \\
\hline
\end{tabular}

* Average weight of 10 untreated checks $=5.5$ grams.

t The soil in the last three tubes was moistened before the sodium chlorate was applied. All other applications were to dry soil.

umns; in the Fresno soil it penetrated almost to the lowest fraction; and in the Stockton soil it was apparently free to move with the moisture, there being no evidence of fixation whatever. The differences in initial toxicity are reflected in these curves and agree with those previously observed.

In the moistened tubes the nutrients were removed as expected; and one other feature appears, at least in the Yolo soil. The toxicity seems consistently higher in the moistened columns of this soil, and slight differences of the same nature occur in the Fresno soil. Since heavy leach- 
ing tends to reduce somewhat the crop-producing power of the soil, the toxicity is increased as might be expected.

Since the breaks in the curves in figure 16 are not sharp, values for the fixing power of these soils, calculated as for arsenic, are not exact.

TABLE 14

The Fixing Power of Columbia fine Sandy Loam for Sodium Chlorate, AS Shown' BY Growth OF INDICATOR Plants* (Harvested April 3, 1934)

\begin{tabular}{|c|c|c|c|c|c|c|c|c|c|c|}
\hline \multirow{2}{*}{ Depth } & \multicolumn{2}{|c|}{$\underset{\text { check }}{\mathrm{H}_{2} \mathrm{O}}$} & \multicolumn{2}{|c|}{$\begin{array}{c}\mathrm{NaClO}_{3} \\
100 \text { p.p.m. }\end{array}$} & \multicolumn{2}{|c|}{$\begin{array}{c}\mathrm{NaClO}_{3} \\
200 \text { p.p.m. }\end{array}$} & \multicolumn{2}{|c|}{$\begin{array}{c}\mathrm{NaClO}_{3} \\
400 \text { p.p.m. }\end{array}$} & \multicolumn{2}{|c|}{$\begin{array}{c}\mathrm{NaClO}_{3} \\
800 \text { p.p.m. }\end{array}$} \\
\hline & Ht. & Wt. & Ht. & Wt. & Ht. & Wt. & Ht. & Wt. & Ht. & Wt. \\
\hline inches & $\mathrm{cm}$ & $g m$ & $\mathrm{~cm}$ & $g m$ & $\mathrm{~cm}$ & $g m$ & $\mathrm{~cm}$ & $g m$ & $\mathrm{~cm}$ & $g m$ \\
\hline $0.0-3.6$ & 26 & 3.9 & 26 & 2.7 & 10 & 0.5 & 7 & 0.1 & 8 & 0.1 \\
\hline $3.6-7.2$ & 23 & 3.3 & 26 & 2.6 & 14 & 0.7 & 8 & 0.1 & 5 & 0.1 \\
\hline $7.2-10.8$ & 24 & 3.5 & 22 & 2.4 & 14 & 0.6 & 8 & 0.1 & 5 & 0.1 \\
\hline $10.8-14.4$ & 26 & 3.0 & 24 & 2.5 & 13 & 0.7 & 14 & 0.2 & 18 & 0.2 \\
\hline $14.4-18.0$ & 26 & 3.7 & 25 & 3.0 & 27 & 2.4 & 14 & 0.6 & 13 & 0.8 \\
\hline $18.0-21.6$ & 26 & 4.2 & 29 & 3.3 & 28 & 3.0 & 28 & 2.9 & 20 & 1.3 \\
\hline 21. 6-25. 2 & 31 & 6.0 & 32 & 4.8 & 30 & 4.6 & 31 & 5.0 & 18 & 2.0 \\
\hline $25.2-28.8$ & 31 & 6.9 & 32 & 8.5 & 31 & 6.4 & 34 & 5.8 & 25 & 3.0 \\
\hline $28.8-32.4$ & 33 & 8.1 & 36 & 9.0 & 32 & 6.3 & 31 & 6.1 & 31 & 4.6 \\
\hline $32.4-36.0$ & 32 & 8.0 & 35 & 9.7 & 32 & 7.5 & 31 & 5.9 & 31 & 6.1 \\
\hline \multirow{2}{*}{ Depth } & \multicolumn{2}{|c|}{$\begin{array}{c}\mathrm{NaClO}_{3} \\
\text { 1,600 p.p.m. }\end{array}$} & \multicolumn{2}{|c|}{$\begin{array}{c}\mathrm{NaClO}_{3} \\
\text { 3,200 p.p.m. }\end{array}$} & \multicolumn{2}{|c|}{$\begin{array}{c}\mathrm{NaClO}_{3} \dagger \\
100 \text { p.p.m. }\end{array}$} & \multicolumn{2}{|c|}{$\begin{array}{c}\mathrm{NaClO}_{3} \dagger \\
400 \text { p.p.m. }\end{array}$} & \multicolumn{2}{|c|}{$\begin{array}{c}\mathrm{NaClO}_{3} \dagger \\
\text { 1,600 p.p.m. }\end{array}$} \\
\hline & Ht. & Wt. & Ht. & Wt. & Ht. & Wt. & Ht. & Wt. & Ht. & Wt. \\
\hline inches & $\mathrm{cm}$ & $g m$ & $\mathrm{~cm}$ & $g m$ & $\mathrm{~cm}$ & $g m$ & $\mathrm{~cm}$ & $g m$ & $\mathrm{~cm}$ & $g m$ \\
\hline $0.0-3.6$ & 0 & 0.0 & 0 & 0.0 & 23 & 2.6 & 6 & 0.1 & 0 & 0.0 \\
\hline $3.6-7.2$ & 0 & 0.0 & 0 & 0.0 & 23 & 2.7 & 7 & 0.3 & 0 & 0.0 \\
\hline $7.2-10.8$ & 0 & 0.0 & 0 & 0.0 & 24 & 2.6 & 5 & 0.1 & 0 & 0.0 \\
\hline $10.8-14.4$ & 0 & 0.0 & 0 & 0.0 & 24 & 3.2 & 5 & 0.1 & 0 & 0.0 \\
\hline $14.4-18.0$ & 0 & 0.0 & 0 & 0.0 & 25 & 3.3 & 6 & 0.1 & 0 & 0.0 \\
\hline $18.0-21.6$ & 0 & 0.0 & 0 & 0.0 & 26 & 3.1 & 6 & 0.1 & 0 & 0.0 \\
\hline $21.6-25.2$ & 6 & 0.1 & 6 & 0.1 & 25 & 3.4 & 21 & 1.7 & 6 & 0.1 \\
\hline $25.2-28.8$ & 26 & 3.2 & 9 & 0.4 & 26 & 2.8 & 22 & 2.1 & 0 & 0.0 \\
\hline $28.8-32.4$ & 29 & 3.9 & 25 & 1.8 & 26 & 3.1 & 23 & 2.9 & 0 & 0.0 \\
\hline $32.4-36.0$ & 29 & 3.7 & 21 & 2.4 & 26 & 3.3 & 24 & 3.0 & 6 & 0.1 \\
\hline
\end{tabular}

* Average weight of 10 untreated checks $=8.4$ grams.

† The soil in the last three tubes was moistened before the sodium chlorate was applied. All other applications were to dry soil.

Obviously the column cannot be divided into two parts, one containing chlorate and the other free from it. The concentration of chlorate decreases gradually downward, especially in the Columbia and Fresno soils; and an average value for the concentration in the upper portion of the tube would not be accurate. Estimates have been made, however, which, though only approximate, are interesting to contrast with those made for the arsenic. For instance, in the tubes moistened with solutions containing 800 p.p.m. of sodium chlorate, the values for the concentration fixed, based on air-dry soil, are as follows: Yolo clay loam, 110 
p.p.m.; Stockton adobe clay, 0 p.p.m.; Fresno sandy loam, 16 p.p.m.; Columbia fine sandy loam, 80 p.p.m. Corresponding values for sodium arsenite were Yolo clay loam, 480 p.p.m.; Stockton adobe clay, 280 p.p.m.; Fresno sandy loam, 131 p.p.m.; Columbia fine sandy loam, 335 p.p.m. The greatest difference is shown by the Stockton soil, which,

TABLE 15

Results of Leaching Tests with Sodium Chlorate* in California Soils, as Shown by Growth of Indicator Plants

\begin{tabular}{|c|c|c|c|c|c|c|c|c|c|}
\hline \multirow{2}{*}{$\begin{array}{c}\text { Soil Type, } \\
\mathrm{NaClO}_{3} \\
\text { concentration, and } \\
\text { harvesting date } \\
(\mathbf{1 9 3 4 )}\end{array}$} & \multirow{2}{*}{ Depth } & \multicolumn{2}{|c|}{$5 \mathrm{~cm} \mathrm{H}_{2} \mathrm{O}$} & \multicolumn{2}{|c|}{$10 \mathrm{~cm} \mathrm{H}_{2} \mathrm{O}$} & \multicolumn{2}{|c|}{$20 \mathrm{~cm} \mathrm{H}_{2} \mathrm{O}$} & \multicolumn{2}{|c|}{$40 \mathrm{~cm} \mathrm{H}_{2} \mathrm{O}$} \\
\hline & & Ht. & Wt. & Ht. & Wt. & Ht. & Wt. & Ht. & Wt. \\
\hline \multirow{11}{*}{$\begin{array}{l}\text { Yolo clay loam; } \\
150 \text { cc } \mathrm{NaClO}_{3} \text { solu- } \\
\text { tion* previously } \\
\text { applied; harvested } \\
\text { May } 18\end{array}$} & inches & $\mathrm{cm}$ & $g m$ & $\mathrm{~cm}$ & $g m$ & $\mathrm{~cm}$ & $g m$ & $\mathrm{~cm}$ & $g m$ \\
\hline & $0.0-3.6$ & 10 & 0.9 & 20 & 2.9 & 22 & 4.2 & 25 & 5.7 \\
\hline & $3.6-7.2$ & 10 & 1.1 & 17 & 2.2 & 22 & 3.8 & 28 & 6.1 \\
\hline & $7.2-10.8$ & 12 & 1.5 & 12 & 1.5 & 20 & 2.5 & 27 & 6.2 \\
\hline & $10.8-14.4$ & 14 & 1.9 & 12 & 1.1 & 20 & 3.1 & 25 & 5.6 \\
\hline & $14.4-18.0$ & 15 & 2.2 & 12 & 1.4 & 20 & 2.7 & 28 & 6.7 \\
\hline & $18.0-21.6$ & 20 & 4.3 & 11 & 1.1 & 20 & 3.0 & 25 & 6.0 \\
\hline & $21.6-25.2$ & 26 & 7.0 & 15 & 2.4 & 19 & 2.1 & 30 & 6.4 \\
\hline & $25.2-28.8$ & 28 & 7.4 & 17 & 3.7 & 19 & 2.4 & 28 & 6.0 \\
\hline & $28.8-32.4$ & 25 & 7.2 & 24 & 5.6 & 20 & 3.1 & 26 & 6.1 \\
\hline & $32.4-36.0$ & 26 & 7.3 & 25 & 7.0 & 23 & 5.2 & 27 & 6.5 \\
\hline \multirow{10}{*}{$\begin{array}{l}\text { Stockton adobe clay; } \\
140 \text { cc } \mathrm{NaClO}_{3} \text { solu- } \\
\text { tion* previously } \\
\text { applied; harvested } \\
\text { April } 30\end{array}$} & $0.0-3.6$ & 4 & 0.1 & 27 & 2.5 & 28 & 2.7 & 23 & 2.3 \\
\hline & $3.6-7.2$ & 4 & 0.1 & 17 & 1.1 & 25 & 2.8 & 25 & 2.2 \\
\hline & $7.2-10.8$ & 4 & 0.1 & 6 & 0.3 & 20 & 1.9 & 22 & 2.0 \\
\hline & $10.8-14.4$ & 6 & 0.2 & 4 & 0.1 & 25 & 2.4 & 23 & 2.4 \\
\hline & 14.4-18.0 & 21 & 1.8 & 4 & 0.1 & 20 & 1.4 & 25 & 2.6 \\
\hline & $18.0-21.6$ & 24 & 2.6 & 5 & 0.2 & 16 & 1.0 & 25 & 2.3 \\
\hline & $21.6-25.2$ & 22 & 2.1 & 6 & 0.4 & 6 & 0.2 & 23 & 2.5 \\
\hline & $25.2-28.8$ & 22 & 1.9 & 15 & 1.1 & 4 & 0.1 & 23 & 2.4 \\
\hline & $28.8-32.4$ & 25 & 2.2 & 21 & 1.7 & 4 & 0.1 & 24 & 2.3 \\
\hline & $32.4-36.0$ & 22 & 2.3 & 22 & 2.0 & 5 & 0.1 & 21 & 1.8 \\
\hline \multirow{10}{*}{$\begin{array}{l}\text { Fresno sandy loam; } \\
90 \text { cc } \mathrm{NaClO}_{3} \text { solu- } \\
\text { tion* previously } \\
\text { applied; harvested } \\
\text { April } 19\end{array}$} & $0.0-3.6$ & 21 & 3.4 & 21 & 4.0 & 20 & 3.7 & 19 & 3.5 \\
\hline & $3.6-7.2$ & 22 & 3.3 & 21 & 4.1 & 21 & 3.7 & 20 & 3.7 \\
\hline & $7.2-10.8$ & 22 & 2.2 & 20 & 3.7 & 21 & 4.1 & 19 & 3.8 \\
\hline & $10.8-14.4$ & 15 & 1.2 & 23 & 2.8 & 20 & 3.9 & 21 & 4.3 \\
\hline & $14.4-18.0$ & 10 & 0.9 & 22 & 3.7 & 20 & 4.2 & 20 & 4.6 \\
\hline & $\{18.0-21.6$ & 10 & 0.6 & 20 & 2.1 & 20 & 4.2 & 21 & 4.2 \\
\hline & $21.6-25.2$ & 15 & 1.3 & 8 & 0.3 & 20 & 3.9 & 21 & 4.4 \\
\hline & 25.2-28.8 & 24 & 2.7 & 8 & 0.3 & 21 & 3.7 & 21 & 4.1 \\
\hline & $28.8-32.4$ & 25 & 3.6 & 8 & 0.4 & 22 & 3.1 & 20 & 4.1 \\
\hline & $32.4-36: 0$ & 25 & 3.3 & 20 & 1.9 & 17 & 1.8 & 20 & 3.9 \\
\hline \multirow{10}{*}{$\begin{array}{l}\text { Columbia fine sandy } \\
\text { loam; } 100 \text { cc } \mathrm{NaClO}_{3} \\
\text { solution* previously } \\
\text { applied; harvested } \\
\text { April } 21\end{array}$} & $0.0-3.6$ & 9 & 0.6 & 18 & 2.0 & 21 & 4.0 & 21 & 4.5 \\
\hline & $3.6-7.2$ & 5 & 0.1 & 3 & 0.1 & 19 & 3.2 & 22 & 5.3 \\
\hline & $7.2-10.8$ & 3 & 0.1 & 3 & 0.1 & 3 & 0.5 & 22 & 4.8 \\
\hline & $10.8-14.4$ & 3 & 0.1 & 8 & 0.7 & 3 & 0.1 & 21 & 4.5 \\
\hline & $14.4-18.0$ & 18 & 1.9 & 6 & 0.2 & 4 & 0.2 & 21 & 4.5 \\
\hline & $18.0-21.6$ & 24 & 4.7 & 7 & 0.5 & 14 & 1.3 & 21 & 3.6 \\
\hline & $21.6-25.2$ & 23 & 5.5 & 14 & 1.1 & 22 & 2.7 & 21 & 3.9 \\
\hline & $25.2-28.8$ & 25 & 5.5 & 21 & 2.3 & 23 & 3.1 & 21 & 4.1 \\
\hline & $28.8-32.4$ & 27 & 6.7 & 22 & 2.8 & 20 & 3.1 & 24 & 3.9 \\
\hline & $32.4-36.0$ & 30 & 6.9 & 22 & 3.4 & 21 & 4.1 & 21 & 4.2 \\
\hline
\end{tabular}

* Shortly before leaching, a 4,000-p.p.m. solution of sodium chlorate was applied to the soils, in amounts varying with the soil type, as indicated. 
though highly colloidal, apparently has no power to hold sodium chlorate above the concentration applied.

Since the fixing power for chlorate is so low, the method previously used in the leaching tests had to be changed. The tubes of soil in these experiments were first moistened slowly with water. Next, the amount of sodium chlorate equivalent to 400 p.p.m. in the volume used for mois-

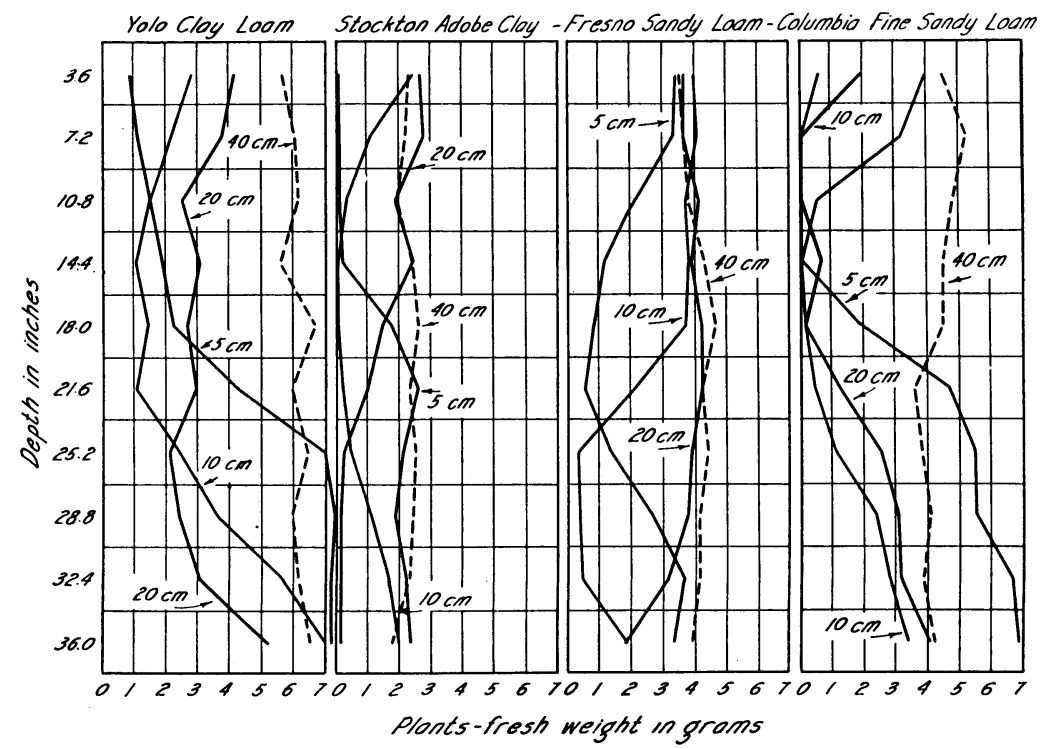

Fig. 17.-The effect of leaching upon the location of sodium chlorate in soil columns as shown by crop yield.

tening was applied, dissolved in one-tenth of this volume or in the volume necessary to moisten the top fraction. After a short time, leaching was started with distilled water. All water and solutions were applied at a rate of 12 drops per minute. The data from these tests appear in table 15; the graphs in figure 17.

These experiments serve to illustrate the relation between moving water in the soil and the location and distribution of chlorate. With low fixing power the chemical moves freely with soil moisture and is displaced readily, whereas with greater fixing power it tends to lag, and greater amounts of water are required to effect a given vertical movement. The differences observed in these tests are great enough to be significant in the field, and they serve to explain many of the anomalous results reported in field trials.

To be of practical value, this work must be repeated in the field in a large number of soils and under a variety of conditions. Though cer- 
tain clues may be taken from plot tests, ${ }^{(6)}$ definite knowledge of the behavior of chlorates in soils must be obtained by soil-testing methods that are subject to considerable control.

One practical application of the testing method described has been made in studying the location and concentration of chlorate residues in the field. Application of chlorate to areas of morning-glory in a field at Davis in the fall of 1930 resulted in sterile spots that were still very much

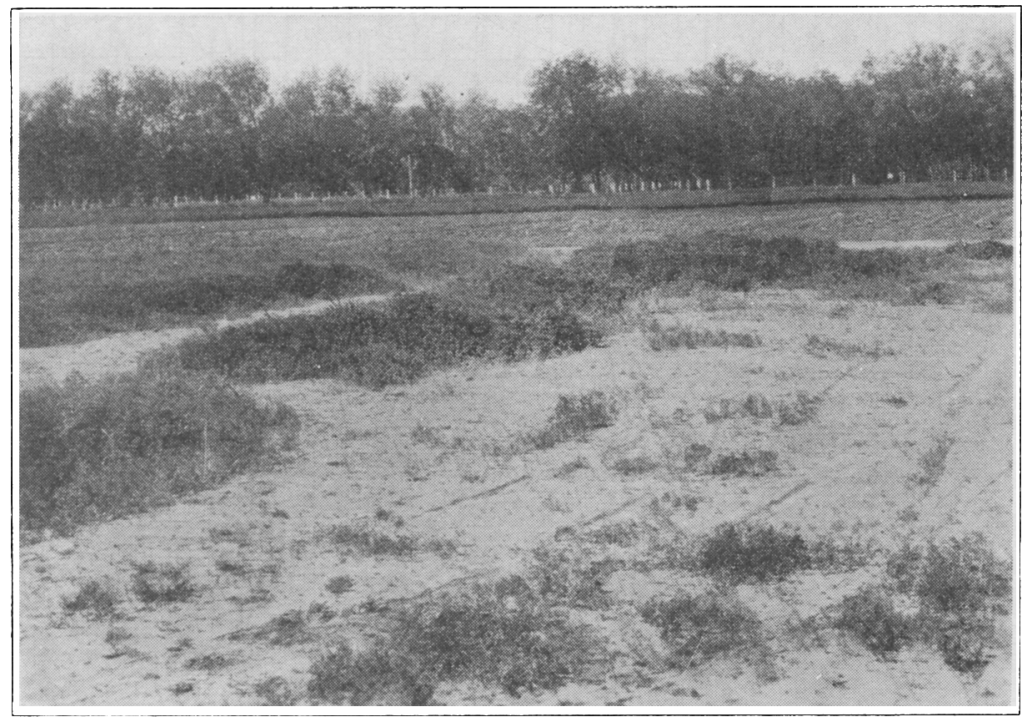

Fig. 18.-Chlorate spots in a planting of fenugreek in a field at Davis. Sodium chlorate was applied in the fall of 1930 at a rate that probably reached 6 pounds per square rod in heavily infested areas. This picture was taken in April, 1933.

in evidence three years later (fig. 18). In May, 1933, the soil was sampled at various depths in these sterile areas and in adjacent fertile areas. Check series were established, using various concentrations of sodium chlorate in the fertile soils from different depths, and corresponding test cultures were made from the sterile areas. By checking the latter against the check series, the approximate concentration of chlorate at the different depths was found. Data from these tests appear in table 16.

The table shows that the top 8 inches of soil contained chlorate at a concentration of 400 p.p.m., or above. A careful comparison of the cultures indicates the following concentrations in the various fractions: 0-2 inches, 500 p.p.m.; 2-4 inches, 400 p.p.m.; 4-8 inches, 800 p.p.m.; 8-12 inches, 150 p.p.m.; 12-16 inches, 50 p.p.m.; $16-20$ inches, 25 p.p.m.

After these determinations, the field containing these sterile areas was diked and irrigated, water being applied almost continuously until 36 
inches had passed through the soil. As soon as the soil had dried sufficiently for sampling, 25 samples were taken from the area illustrated in figure 18. The A samples were taken at intervals of 1 rod along the dike, which appears as a barren strip a bit above center on the left side of the

TABLE 16

Toxicity of Sodium Chlorate in Yolo Fine Sandy Loam from Field Three Years After Application, as Compared with That from Samples Having KNown Concentrations

(Toxicity shown by growth of indicator plants)

\begin{tabular}{|c|c|c|c|c|c|c|c|c|c|c|c|c|c|}
\hline \multirow{3}{*}{$\begin{array}{l}\text { Source of } \\
\text { sample }\end{array}$} & \multirow{3}{*}{$\begin{array}{c}\mathrm{NaClO}_{3} \\
\text { added, } \\
\text { p.p.m. } \\
\text { of } \\
\text { air-dry } \\
\text { soil }\end{array}$} & \multicolumn{12}{|c|}{ Depth from which sample was taken } \\
\hline & & \multicolumn{2}{|c|}{$0-2$ inches } & \multicolumn{2}{|c|}{ 2-4 inches } & \multicolumn{2}{|c|}{ 4-8 inches* } & \multicolumn{2}{|c|}{ 8-12 inches* } & \multicolumn{2}{|c|}{$12-16$ inches* } & \multicolumn{2}{|c|}{$16-20$ inches* } \\
\hline & & Ht. & Wt. & Ht. & Wt. & Ht. & Wt. & Ht. & Wt. & Ht. & Wt. & Ht. & Wt. \\
\hline & p.p.m. & $\mathrm{cm}$ & $g m$ & $\mathrm{~cm}$ & $g m$ & $\mathrm{~cm}$ & $g m$ & $\mathrm{~cm}$ & $g m$ & $\mathrm{~cm}$ & $g m$ & $\mathrm{~cm}$ & $g m$ \\
\hline No. 1 .................. & ............. & 2 & 0.1 & 3 & 0.1 & 0 & 0.0 & 3 & 0.1 & 11 & 0.6 & 16 & 1.5 \\
\hline \multirow{4}{*}{$\begin{array}{l}\text { Chlorate spot } \\
\text { No. } 2\end{array}$} & & & & & & & & & & & & & \\
\hline & $\ldots \ldots \ldots .$. & 3 & 0.1 & 4 & 0.1 & 0 & 0.0 & 4 & 0.1 & 9 & 0.6 & 15 & 1.2 \\
\hline & 25 & 17 & 1.3 & 16 & 1.2 & $16^{*}$ & $1.3^{*}$ & $\ldots{ }^{*}$ & $\ldots . . .{ }^{*}$ & $16^{*}$ & $1.3^{*}$ & $\ldots{ }^{*}$ & $\ldots . . .{ }^{*}$ \\
\hline & 50 & 12 & 1.0 & 13 & 0.9 & 8 & 0.6 & $\ldots$. & $\ldots . . .$. & 12 & 0.7 & $\ldots$ & $\ldots \ldots$. \\
\hline Check series & 100 & 8 & 0.5 & 6 & 0.4 & 5 & 0.3 & $\ldots$. & $\ldots . .$. & 5 & 0.3 & $\ldots$. & $\ldots \ldots$. \\
\hline with known & 200 & 4 & 0.2 & 4 & 0.2 & 2 & 0.1 & $\ldots$ & ....... & 4 & 0.1 & .... & ....... \\
\hline concentrations & 400 & 4 & 0.2 & 3 & 0.1 & 2 & 0.1 & $\ldots$ & $\ldots \ldots$. & 1 & 0.1 & $\ldots$ & $\ldots . . .$. \\
\hline \multirow[t]{3}{*}{ of $\mathrm{NaClO}_{3}$} & 600 & 0 & 0.1 & 0 & 0.0 & 0 & 0.0 & $\ldots$. & $\ldots . .$. & 0 & 0.0 & $\ldots$. & $\ldots . .$. \\
\hline & 800 & 0 & 0.0 & 0 & 0.0 & 0 & 0.0 & $\ldots$. & $\ldots \ldots$ & 0 & 0.0 & $\ldots$. & $\ldots \ldots$. \\
\hline & $(1,000$ & 0 & 0.0 & 0 & 0.0 & 0 & 0.0 & $\ldots$ & $\ldots \ldots$ & 0 & 0.0 & $\ldots$. & $\ldots \ldots$. \\
\hline Checks with no & 0 & 17 & 2.2 & 17 & 2.2 & $16^{*}$ & $2.4^{*}$ & $\ldots{ }^{*}$ & $\ldots . . . *^{*}$ & $16^{*}$ & $2.0^{*}$ & $\ldots{ }^{*}$ & $\ldots . . .{ }^{*}$ \\
\hline $\mathrm{NaClO}_{3}$ added & 0 & 16 & 2.2 & 17 & 2.4 & 17 & 2.5 & $\ldots$ & $\ldots \ldots$ & 17 & 2.2 & $\ldots$. & $\ldots . .$. \\
\hline
\end{tabular}

* In the check series, the 4-8 inch and 8-12 inch samples were combined, and likewise the 12-16 inch and 16-20 inch samples.

picture. The B samples were taken through the strip of normal vegetation to the right of the dike, the $\mathrm{C}$ and $\mathrm{D}$ samples from the barren area in the foreground, and the $\mathrm{E}$ samples from an adjoining check on the right that had never been treated with chlorate. The checks were samples of air-dry soil from bins in the head-house. Table 17 shows the growth of plants in these samples.

The only sample showing definite signs of chlorate effect was A4. Since these samples were all from the top 4 inches and since the top of the dike was not entirely wet by the irrigation water, this particular sample probably was not leached completely.

Samples to a depth of 42 inches were taken at a number of these locations; the results appear in table 18.

Here again the only significant differences appear in the soil of the A4 position. The higher concentration of chlorate at the lower levels indicates that lateral movement of water was sufficient to move the chlorate 
down in the soil under the dike but to a lesser extent than in the flooded areas. Location E3 was outside the flooded area, and the greater crop in the top two samples gives a measure of the effects of the flooding on the treated areas. As these results show, leaching is a satisfactory method for removing chlorate from the soil. Different soil types react differently, however; and a testing method such as the one described should give a practical means for determining the effectiveness of a given treatment. Samples can be taken while the soil is fairly moist; and, if the chlorate has not been sufficiently displaced, leaching could be resumed with little loss of time or effort. The field mentioned above was planted

TABLE 17

Growth of Oats in SoIls from Leached Chlorate Spots and Untreated SoIls

\begin{tabular}{|c|c|c|c|c|c|c|c|c|c|c|c|c|}
\hline \multirow{2}{*}{ Sample } & \multicolumn{2}{|c|}{ Series A } & \multicolumn{2}{|c|}{ Series B } & \multicolumn{2}{|c|}{ Series C } & \multicolumn{2}{|c|}{ Series D } & \multicolumn{2}{|c|}{ Series. E } & \multicolumn{2}{|c|}{ Check } \\
\hline & Ht. & Wt. & Ht. & Wt. & Ht. & Wt. & Ht. & Wt. & Ht. & Wt. & Ht. & Wt. \\
\hline & $\mathrm{cm}$ & $g m$ & $\mathrm{~cm}$ & $g m$ & $\mathrm{~cm}$ & $g m$ & $\mathrm{~cm}$ & $g m$ & $\mathrm{~cm}$ & $g m$ & $\mathrm{~cm}$ & $g m$ \\
\hline 1.. & 20 & 3.7 & 18 & 3.2 & 17 & 2.9 & 18 & 2.8 & 18 & 3.1 & 17 & 2.7 \\
\hline 2. & 17 & 2.4 & 19 & 3.5 & 18 & 3.3 & 19 & 3.5 & 19 & 3.7 & 18 & 2.9 \\
\hline $3 . .$. & 17 & 3.0 & 17 & 3.3 & 18 & 3.1 & 18 & 3.2 & 18 & 3.1 & 18 & 2.9 \\
\hline 4 & 14 & 1.7 & 20 & 3.9 & 19 & 3.0 & 19 & 3.2 & 20 & 3.6 & 20 & 2.9 \\
\hline 5 & 18 & 3.3 & 20 & 3.2 & 19 & 2.9 & 19 & 2.7 & 22 & 3.9 & 19 & 2.5 \\
\hline
\end{tabular}

to alfalfa in February, 1934; and the crop had shown no effect of chlorate by August, 1934, and appeared entirely normal.

Possibly a testing method similar to the one just described can be devised for studying the distribution of chlorate, applied under a certain degree of control, to various soils in the field. Such studies would form a connecting link between greenhouse work and plot tests and should give a much more accurate picture of the behavior of chlorate in soils and its effects upon plants than has been obtained from plot work alone.

Discussion of Sodium Chlorate Studies.-Though the spraying of growing weeds is commonly practiced and though certain chemical sprays are fairly effective against deep-rooted perennials, treatments designed to kill such weeds by foliar absorption and translocation of the poison through the plant are subject to a rigid set of requirements. When all these can be met, the acid arsenical method ${ }^{(4,5)}$ seems the logical one to use, being low in initial cost and having no residual effects. Where these requirements cannot be met, sodium chlorate seems to promise the greatest general usefulness. Under these conditions, however, the principal action of chlorate is apparently through the soil by root absorption.

In order to make the most efficient use of chlorate by this method, its behavior in soils should be known. Its toxic limits, as determined by soil 
type and species susceptibility, are important; and its general reaction to the quantity and movement of soil moisture must be understood.

The results reported in this paper show the large differences in toxicity encountered in soil types that may not be widely separated in the field. The soil-tube tests indicate the nature of the forces involved in the penetration of chlorate into soils and the requirements for its movement and removal. The companion paper in this issue ${ }^{(6)}$ indicated the type of plant responses that follow the use of chlorates. This information, coupled with an accurate knowledge of the root distribution of noxious weeds, should provide a more logical basis for experimental

TABLE 18

Distribution of Chlorate in the Soll of Leached Chlorate Spots, as Shown by Growth of Indicator Plants

\begin{tabular}{|c|c|c|c|c|c|c|c|c|c|c|c|c|c|c|}
\hline \multirow{2}{*}{ Depth } & \multicolumn{2}{|c|}{ Sample A-4 } & \multicolumn{2}{|c|}{ Sample B-3 } & \multicolumn{2}{|c|}{ Sample C-2 } & \multicolumn{2}{|c|}{ Sample C-4 } & \multicolumn{2}{|c|}{ Sample D-1 } & \multicolumn{2}{|c|}{ Sample D-5 } & \multicolumn{2}{|c|}{ Sample E-3 } \\
\hline & Ht. & Wt. & Ht. & Wt. & Ht. & Wt. & Ht. & Wt. & Ht. & Wt. & Ht. & Wt. & Ht. & W t. \\
\hline inches & $\mathrm{cm}$ & $g m$ & $\mathrm{~cm}$ & $g m$ & $\mathrm{~cm}$ & $g m$ & $\mathrm{~cm}$ & $g m$ & $\mathrm{~cm}$ & $g m$ & $\mathrm{~cm}$ & $g m$ & $\mathrm{~cm}$ & $g m$ \\
\hline $0-6$ & 11 & 0.8 & 18 & 2.5 & 18 & 2.6 & 18 & 2.9 & 18 & 2.5 & 17 & 1.9 & 22 & 3.6 \\
\hline $6-12$ & 14 & 1.2 & 18 & 2.6 & 18 & 2.5 & 17 & 2.1 & 14 & 2.0 & 16 & 2.0 & 22 & 3.2 \\
\hline $12-18$ & 15 & 1.4 & 16 & 2.4 & 19 & 2.7 & 17 & 2.5 & 17 & 2.8 & 18 & 2.1 & 17 & 2.2 \\
\hline $18-24$ & 16 & 1.5 & 16 & 1.8 & 16 & 2.2 & 19 & 2.4 & 16 & 1.7 & 20 & 2.3 & 18 & 2.4 \\
\hline 24-30 & 15 & 1.2 & 17 & 1.8 & 17 & 2.0 & 15 & 1.5 & 16 & 2.0 & 16 & 1.5 & 19 & 2.3 \\
\hline $30-36$ & 9 & 0.6 & 17 & 1.7 & 19 & 2.4 & 18 & 2.0 & 17 & 2.0 & 15 & 1.5 & 17 & 1.9 \\
\hline $36-42$ & 9 & 0.5 & 16 & 1.5 & 19 & 1.7 & 18 & 1.6 & 16 & 1.7 & 15 & 1.4 & 18 & 2.0 \\
\hline
\end{tabular}

work on control methods than has been available in the past. Though the results of the experiments described in the present paper are fragmentary and apply only to the four soils used, with liberal interpretation in their application they should point the way to more critical work under field conditions. At least they indicate the possibility of developing an accurate and reliable weed control practice.

\section{SUMMARY}

Sodium Arsenite.-Variable results from field-plot tests on soil sterilization with sodium arsenite indicate the need for definite knowledge concerning the toxicity and fixing of this chemical in California soils.

A method has been developed for studying these problems by using a biological test for the toxicant in soils.

Compared with several soil sterilants on a cost basis, trivalent arsenic proved to be the most feasible chemical for soil sterilization.

Toxicity of arsenic was greatest in Fresno sandy loam and lowest in Yolo clay loam. Stockton adobe clay and Columbia fine sandy loam were intermediate. 
Loss of toxicity with time and cropping was greatest in the Yolo soil and lowest in Fresno sandy loam. Here, again, the other two soils were intermediate.

Yolo clay loam has the strongest fixing power for arsenic, being able to hold over four times as much as Fresno sandy loam from solutions of equal concentration. The Stockton and Columbia soils held somewhat over twice as much.

The amount of arsenic held by all four soils was greater with increased concentration of the solutions applied.

The strong fixing of arsenic in the Yolo clay loam was shown again in the leaching tests. After movement of 160 surface centimeters of water through the soil, the top 4 inches was still sterile, and the chemical had not gone down below the 16-inch level.

Arsenic moved down through Stockton adobe clay more readily with leaching. With 160 surface centimeters of leaching, toxicity had decreased in the top 4 inches, but the remainder of the column was sterile.

Columbia fine sandy loam was intermediate between the Yolo and Stockton in the leaching tests.

Fresno sandy loam showed the lowest fixing power. Leaching with 160 surface centimeters of water practically removed the toxicant from the soil column.

Though the results of these experiments cannot be applied directly to soil sterilization in the field, the knowledge gained is very valuable in interpreting field-plot tests and has an integral part in developing an intelligent practice.

Sodium Chlorate.-Experiments indicate that the most successful use of sodium chlorate as a herbicide results from soil application and absorption by roots. For optimum results by this method the operator should understand the behavior of chlorate in soils.

Toxicity of sodium chlorate was highest in Stockton adobe clay and lowest in Yolo clay loam. It was only slightly higher in the Columbia fine sandy loam and intermediate in Fresno sandy loam.

The loss of toxicity with cropping was greater with the third crop than with the second. This is probably related to the increasing temperature as the season advanced.

The fixing power of the four soils was much less for chlorate than for sodium arsenite.

In the Yolo clay loam more chemical was fixed from a slowly moving solution. Rate of moistening had no effect in the Fresno sandy loam.

The Yolo and Columbia soils were able to hold the chemical within the top halves of the 36 -inch columns from solutions up to 400 p.p.m. in concentration. In the Fresno soil it penetrated through nine-tenths of 
the columns. The Stockton soil apparently has no fixing power for sodium chlorate.

Chlorate toxicity was higher in columns previously moistened with distilled water than in those moistened only with the chlorate solutions.

Leaching with distilled water moved the chlorate downward in the soil columns. Forty surface centimeters of water were sufficient to remove the chlorate from the Yolo and Columbia soils. Even less water was required to leach the other two soils free of chemical.

Sodium chlorate was present in the top 20 inches of the soil from sterile areas in a field sprayed three years previously to kill morning-glory.

Leaching with 36 surface inches of irrigation water successfully removed the chemical, and alfalfa was subsequently seeded. No toxic effect could be observed in the alfalfa during the first year. 


\section{LITERATURE CITED}

\section{${ }^{1}$ Aslander, Alfred.}

1926. Chlorates as plant poisons. Jour. Amer. Soc. Agron. 18:1101-1102.

${ }^{2}$ A SLANDER, ALFRED.

1928. Experiments on the eradication of Canada thistle, Cirsium arvense, with chlorates and other herbicides. Jour. Agr. Research 36:915-934.

${ }^{3}$ BaLl, W. S., B. A. Madson, and W. W. RobBins.

1931. The control of weeds. California Agr. Ext. Cir. 54:1-68.

${ }^{4}$ Craftis, A. S., and P. B. Kennedy.

1930. Physiology of Convolvulus arvensis (morning-glory or bindweed) in relation to its control by chemical sprays. Plant Physiol. 3:329-344.

${ }^{5}$ Craftrs, A. S.

1933. The use of arsenical compounds in the control of deep-rooted perennial weeds. Hilgardia 7(9):361-372.

${ }^{B}$ CRAFTs, A. S.

1935. Factors influencing the effectiveness of sodium chlorate when used as an herbicide. Hilgardia $9(9): 437-457$.

${ }^{7}$ Gray, George P.

1919. Tests of chemical means for the control of weeds. Univ. California Pubs. Agr. Sci. 4:67-97.

${ }^{8}$ Jones, L. R., and W. A. ORTON.

1899. Killing weeds with chemicals. Vermont Agr. Exp. Sta. 12th Annual Rept. p. 182-188.

${ }^{\circ}$ Loomis, W. E., Russell Bissey, and E. V. Smith.

1931. Chlorates as herbicides. Science 74:485.

${ }^{10}$ Loomis, W. E., E. V. Smith, Russelu Bissey, and L. C. ARnold.

1933. The absorption and movement of sodium chlorate when used as an herbicide. Jour. Amer. Soc. Agron. 25:724-739.

${ }^{11}$ Muenscher, W. C.

1932. Killing perennial weeds with chlorates during winter. New York (Cornell) Agr. Exp. Sta. Bul. 542:1-8.

${ }^{12}$ SHAw, C. F.

1927. The basis of classification and key to the soils of California. First Internatl. Cong. Soil Sci. Proc. and Papers 4:1-39.

${ }^{13}$ Schulz, E. R., and Noer F. Thompson.

1925. Some effects of sodium arsenite when used to kill the common barberry. U. S. Dept. Agr. Dept. Bul. 1316:1-18.

${ }^{14}$ STONE, G. E.

1909. Effects of chemicals on vegetation. Massachusetts Agr. Exp. Sta. 21st Ann. Rept., p. 62-72.

${ }^{15}$ Thompson, Noet F., and W. W. Robbins.

1926. Methods of eradicating the common barberry (Berberis vulgaris L.). U. S. Dept. Agr. Dept. Bul. 1451:1-46. 